\title{
Executive Summary of Propulsion on the Orion Abort Flight-Test Vehicles
}

\author{
Daniel S. Jones ${ }^{1}$ and Syri J. Koelfgen ${ }^{2}$ \\ NASA Dryden Flight Research Center, Edwards, California, 93523 \\ Marvin W. Barnes, ${ }^{3}$ Rachel J. McCauley, ${ }^{4}$ and Terry M. Wall ${ }^{5}$ \\ NASA Marshall Space Flight Center, Huntsville, Alabama, 35812 \\ Brian D. Reed ${ }^{6}$ \\ NASA Glenn Research Center, Cleveland, Ohio, 44135 \\ and \\ C. Miguel Duncan ${ }^{7}$ \\ TASC Rocket Systems Launch Program, Kirtland AFB, New Mexico, 87117
}

\begin{abstract}
The NASA Orion Flight Test Office was tasked with conducting a series of flight tests in several launch abort scenarios to certify that the Orion Launch Abort System is capable of delivering astronauts aboard the Orion Crew Module to a safe environment, away from a failed booster. The first of this series was the Orion Pad Abort 1 Flight-Test Vehicle, which was successfully flown on May 6, 2010 at the White Sands Missile Range in New Mexico. This paper provides a brief overview of the three propulsive subsystems used on the Pad Abort 1 Flight-Test Vehicle. An overview of the propulsive systems originally planned for future flight-test vehicles is also provided, which also includes the cold gas Reaction Control System within the Crew Module, and the Peacekeeper first stage rocket motor encased within the Abort Test Booster aeroshell. Although the Constellation program has been cancelled and the operational role of the Orion spacecraft has significantly evolved, lessons learned from Pad Abort 1 and the other flight-test vehicles could certainly contribute to the vehicle architecture of many future human-rated space launch vehicles.
\end{abstract}

\section{Nomenclature}

$\begin{array}{ll}\text { AA } & =\text { Ascent Abort } \\ \text { ACM } & =\text { Attitude Control Motor } \\ \text { AFB } & =\text { Air Force Base } \\ \text { AFT } & =\text { Abort Flight Test } \\ \text { AM } & =\text { Abort Motor } \\ \text { ATB } & =\text { Abort Test Booster } \\ \text { ATK } & =\text { Alliant Techsystems, Inc. } \\ \text { BATES } & =\text { ballistic test evaluation system } \\ \text { BKNO }_{3} & =\text { boron potassium nitrate } \\ \text { CEV } & =\text { Crew Exploration Vehicle }\end{array}$

${ }^{1}$ Aerospace Engineer, Aerodynamics and Propulsion Branch, P.O. Box 273/MS 2228, AIAA Senior Member.

${ }^{2}$ Aerospace Engineer, Aerodynamics and Propulsion Branch, P.O. Box 273/MS 2228, AIAA Senior Member.

${ }^{3}$ Aerospace Engineer, Solid Separation and Maneuvering Systems Branch, MS 4205-105G.

${ }^{4}$ Aerospace Engineer, Solid Separation and Maneuvering Systems Branch, MS 4205-105G.

${ }^{5}$ Aerospace Engineer, Solid Separation and Maneuvering Systems Branch, MS 4205-105F.

${ }_{7}^{6}$ Aerospace Engineer, Space Propulsion Branch, 21000 Brookpark Road/MS 86-8.

${ }^{7}$ TASC Project Manager - Abort Test Booster, 3548 Aberdeen Avenue, SE. 


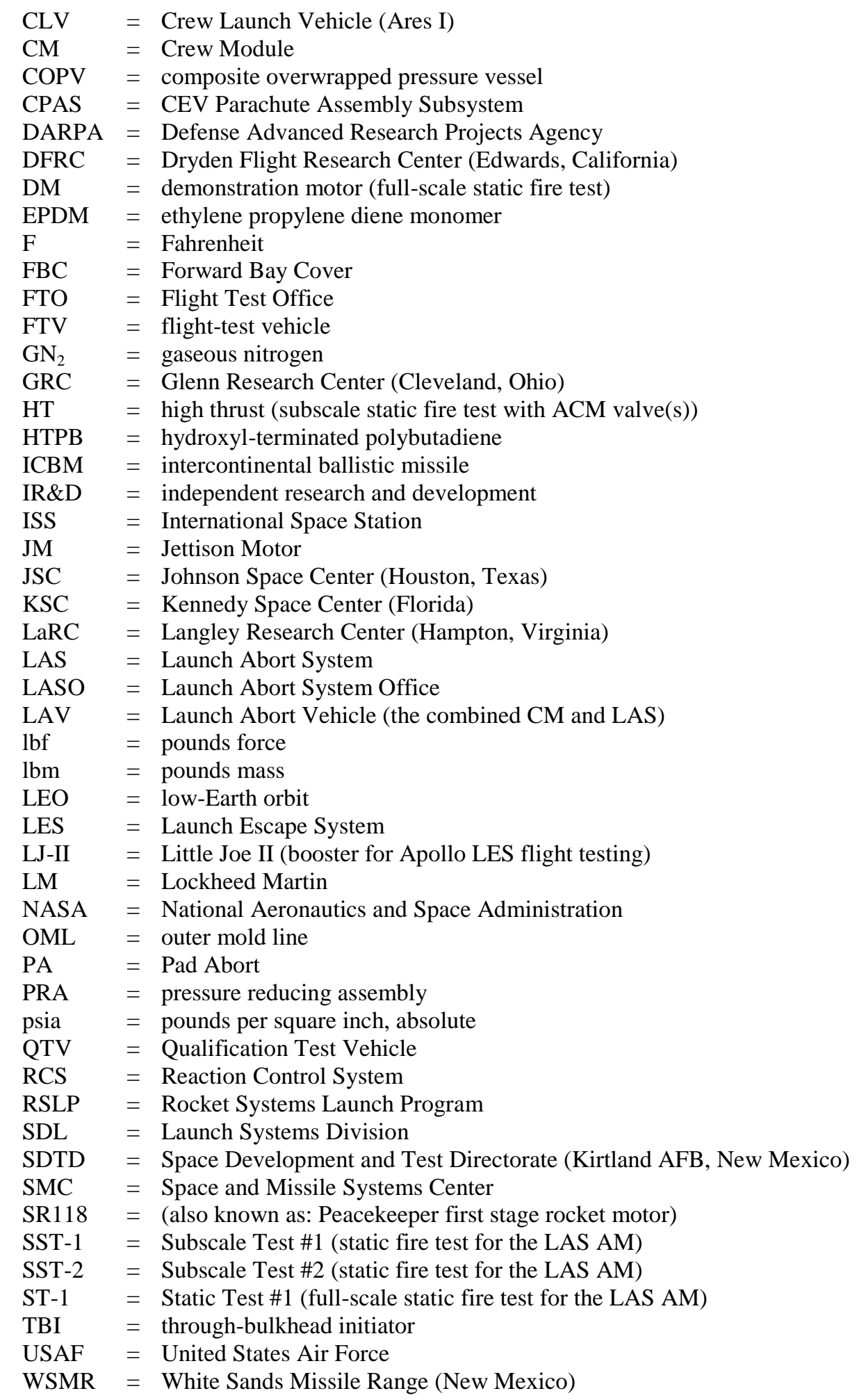

\section{Introduction}

$\mathbf{B}$ ackground on Constellation and Orion will now be introduced, including some top-level detail on the Orion Launch Abort System. This will provide the reader with the logic behind a review of the Apollo flight-test manifest, as well as the requirement for developing the Orion Abort Flight Test program. 


\section{A. Constellation Program}

On January 14, 2004 President George W. Bush articulated the new vision for space exploration, outlining several monumental goals for the United States of America to achieve over decades to come. The National Aeronautics and Space Administration (NASA) would be responsible for the implementation of this vision, with one of the four goals being to "Extend human presence across the solar system, starting with a human return to the Moon by the year 2020, in preparation for human exploration of Mars and other destinations."

Shortly thereafter, in February of 2004, NASA provided the framework for fulfilling the President's vision, noting that, "NASA will pursue this Vision as our highest priority." "NASA also created the Constellation Program, a program focused on developing the spacecraft and systems that would take astronauts to the International Space Station (ISS) after retirement of the Space Shuttle, and eventually return humans to the Moon. The Constellation Program included development of the Ares I rocket, Ares V rocket, Orion Crew Exploration Vehicle (CEV), and Altair lunar lander. ${ }^{2}$

The Ares I Crew Launch Vehicle (CLV) was being developed as an in-line, two-stage rocket topped by the Orion CEV. ${ }^{3}$ The Ares I CLV would loft the Orion spacecraft into low-Earth orbit (LEO) to then rendezvous and dock with either the ISS, or with the Altair lunar lander and Earth departure stage. Figure 1 shows an artist's rendition of the Ares I CLV during ascent. ${ }^{4}$

The primary focus of the Constellation/Orion architecture was crew safety, which is critical during the development of any humanrated launch system and spacecraft. Although the Constellation Program was cancelled in 2010, several technologies from Constellation could be leveraged to reestablish America's access to space. Many of these technologies were developed for the Orion spacecraft.

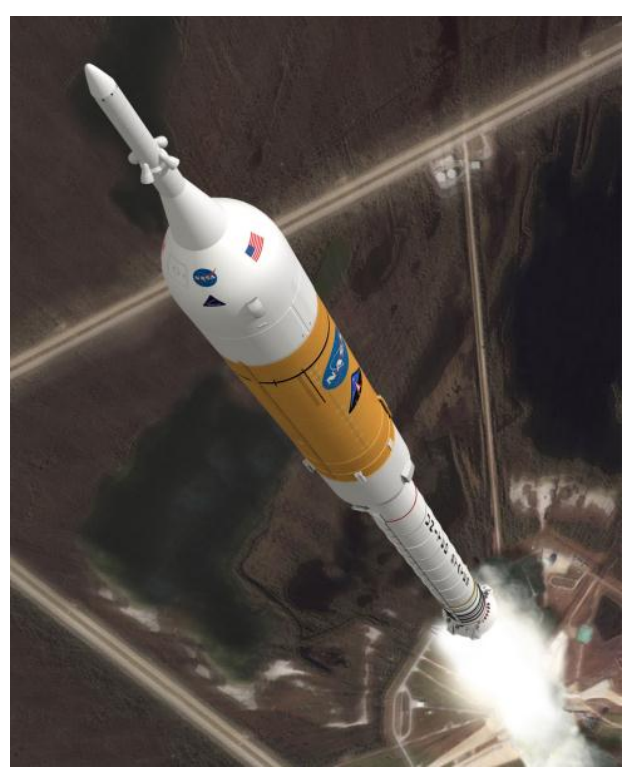

Figure 1. Ares I CLV during ascent.

\section{B. Project Orion}

The Orion CEV was being developed as NASA's flagship for space exploration programs beyond LEO, and was a key element of NASA's Constellation Program to explore the Moon, Mars, and beyond. The Orion CEV was also envisioned to replace the Space Shuttle after it was retired, and become America's new, safe, affordable, reliable, versatile, and reusable space exploration vehicle. The Orion CEV consisted of four primary systems: the Launch Abort System (LAS), Crew Module (CM), Service Module, and Spacecraft Adapter. Figure 2 shows an artist's early rendition of each of these systems from top to bottom, respectively. ${ }^{5}$ Although the Orion CEV has significantly evolved into the Multi-Purpose Crew Vehicle, the primary goal is still focused on human exploration beyond LEO.

The sole purpose of the LAS was to provide the Orion crew with an emergency escape capability, if needed, during the launch of the Orion CEV on top of the Ares I CLV. The CM was a capsule-shaped vehicle designed for the transport of a crew of up to four to lunar orbit, or up to six to the ISS, and could also be utilized for transport of cargo. The Service Module was to provide propulsion, electrical power, and fluids storage capability for the Orion CM. Finally; the Spacecraft Adapter would provide a structural transition between the Ares I CLV and the Orion CEV. ${ }^{5}$

In July of 2005 NASA began working with two potential CEV contractor teams to perform concept refinement, trade studies, analysis of requirements, and preliminary design options. In August 2006, NASA announced the new CEV will be named Orion, ${ }^{6}$ and later that month selected Lockheed Martin (LM) in Denver, Colorado as the prime contractor to design, develop, and build Orion. ${ }^{7}$ The Lockheed Martin Corporate headquarters is based in Bethesda, Maryland.

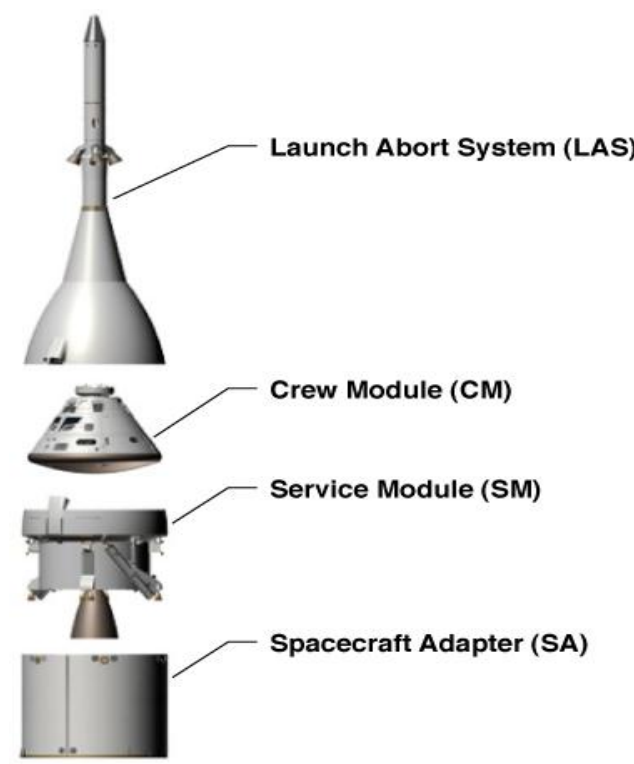

Figure 2. Expanded view of the Orion CEV. 
The new Constellation/Orion architecture had several key advantages over the Space Shuttle architecture in areas of crew safety, one of which is due to the inclusion of the LAS in the Orion architecture. This additional system provided the possibility of a crew escape in the unlikely event that the primary propulsion system failed.

\section{Orion Launch Abort System}

A key feature of the new Orion spacecraft design was the additional safety provided by the Orion LAS, which was mounted on top of the Orion CM (and on top of the Ares I CLV stack). The combination of the LAS and CM, defined as the Launch Abort Vehicle (LAV), would separate from a failed booster in the event of an emergency. In this scenario, the LAV could safely pull the crew out of danger in the event of an emergency on the launch pad or during the climb to Earth orbit. ${ }^{8}$ In a nominal flight scenario, where the astronauts are not required to abort their flight plan, the LAS would be discarded during a nominal Ares I CLV second stage operation. ${ }^{9}$

The LAS consists of several subsystems, three of which are solid rocket motors: the Abort Motor (AM), Jettison Motor (JM), and Attitude Control Motor (ACM). Figure 3 shows an early design model of the LAS integrated with the Orion CM, with each of these primary subsystems labeled. ${ }^{8}$ The LAS AM provides the primary propulsive force that is responsible for pulling the Orion CM away to safety. The LAS ACM is utilized for LAV directional control during the ascent, and provides the thrust force necessary to reorient the LAV in a heat-shield forward flight configuration. While the LAV is in the heat-shield forward flight configuration, the LAS JM is utilized to discard the LAS, enabling the Orion $\mathrm{CM}$ to begin the parachutephase of its mission. Figure 4 shows a typical pad abort flight sequence of events.

The development of the Orion LAS is led by the Exploration and Flight Projects Directorate at the NASA Langley Research Center (LaRC) in Hampton, Virginia. The LAS Office (LASO) at NASA LaRC leads this effort on behalf of the Orion Project Office located at

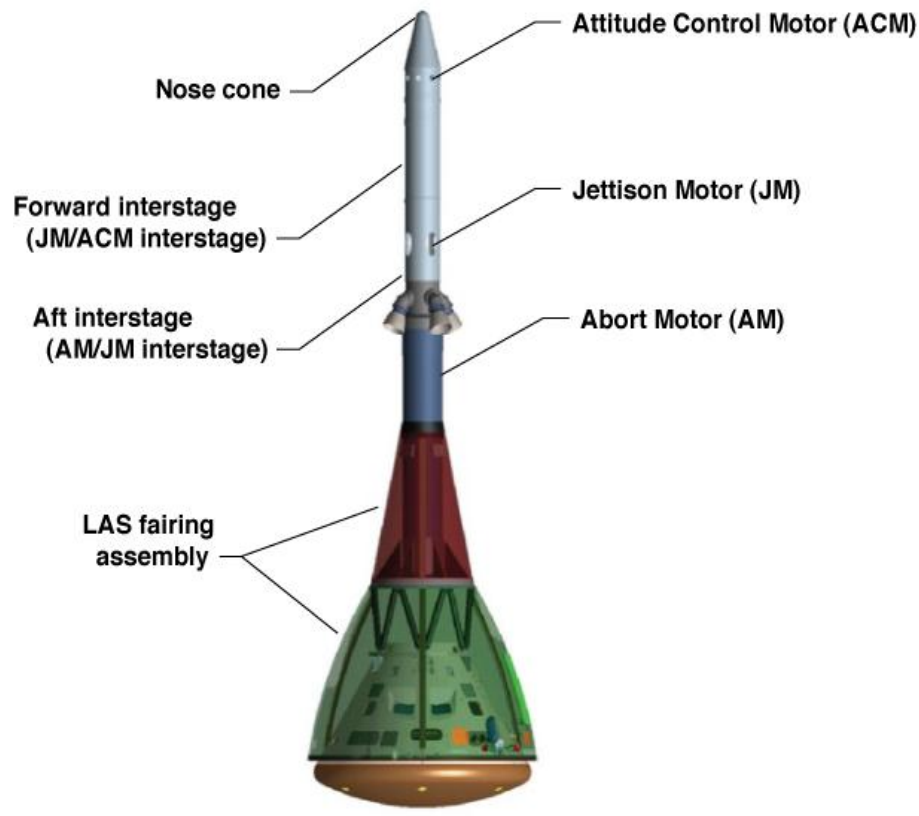

Figure 3. View of the Orion LAS mated with the CM, including all the primary LAS subsystems.

NASA's Johnson Space Center (JSC), in Houston, Texas. NASA JSC is leading all facets of Orion spacecraft development, originally for the Constellation Program, and now evolved into the Orion Multi-Purpose Crew Vehicle. In addition, the NASA Marshall Space Flight Center in Huntsville, Alabama is partnered with LaRC in LAS development. LM is NASA's prime contractor for the design, development, testing, and construction of Orion, including the $\mathrm{LAS}^{8}$

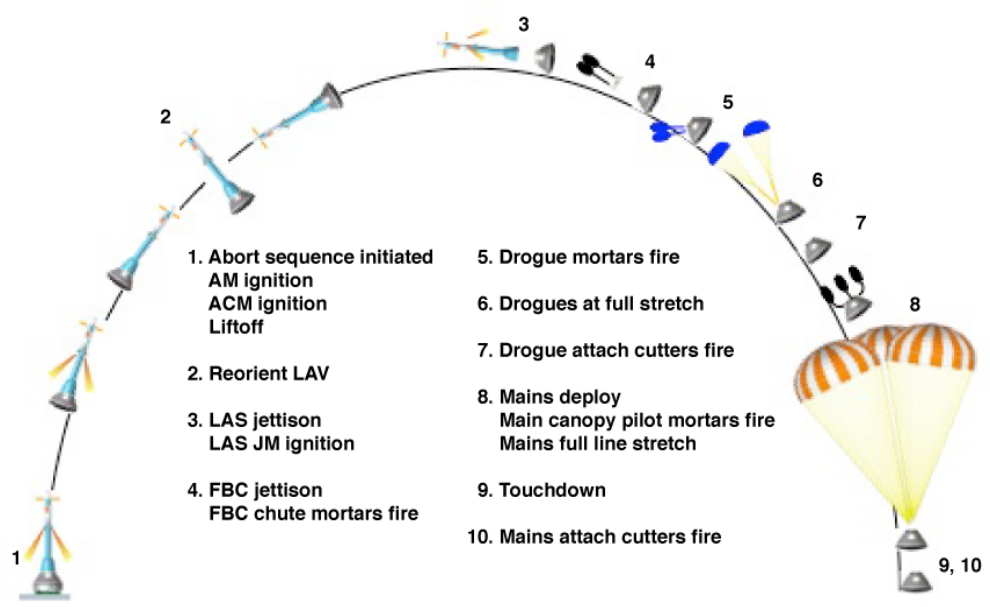

Figure 4. Typical Pad Abort flight sequence of events. 


\section{Apollo Launch Escape System Qualification Flight Tests}

Since the Orion LAS has several fundamental similarities to the Apollo Launch Escape System (LES), one would expect the Orion LAS to follow a somewhat similar path to demonstrate it was qualified for human-rated flight. Accordingly, it was advantageous to review the Apollo LES qualification flight-test program. The Apollo flight vehicle architecture included a system capable of allowing the astronauts within the Command Module to escape to safety during a launch, which was provided by the Apollo LES. Figure 5 shows a photo (as viewed from the launch tower) of Apollo 11 during liftoff. ${ }^{10}$ Figure 6 shows more detail on the Apollo Command Module and LES. The Apollo LES architecture was comprised of three solid rocket motors: (1) the Launch-Escape Motor, (2) Pitch-Control Motor, and (3) Tower-Jettison Motor. ${ }^{11}$

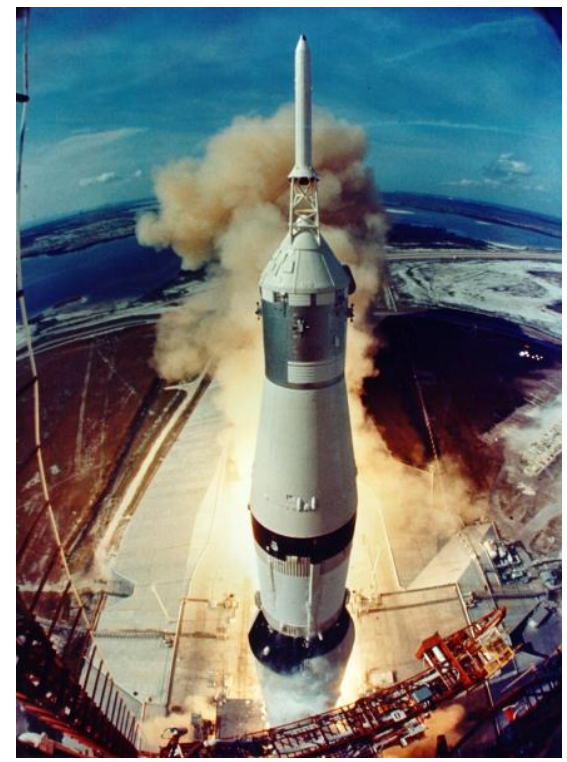

Figure 5. Apollo 11 during liftoff, as viewed from the launch tower.

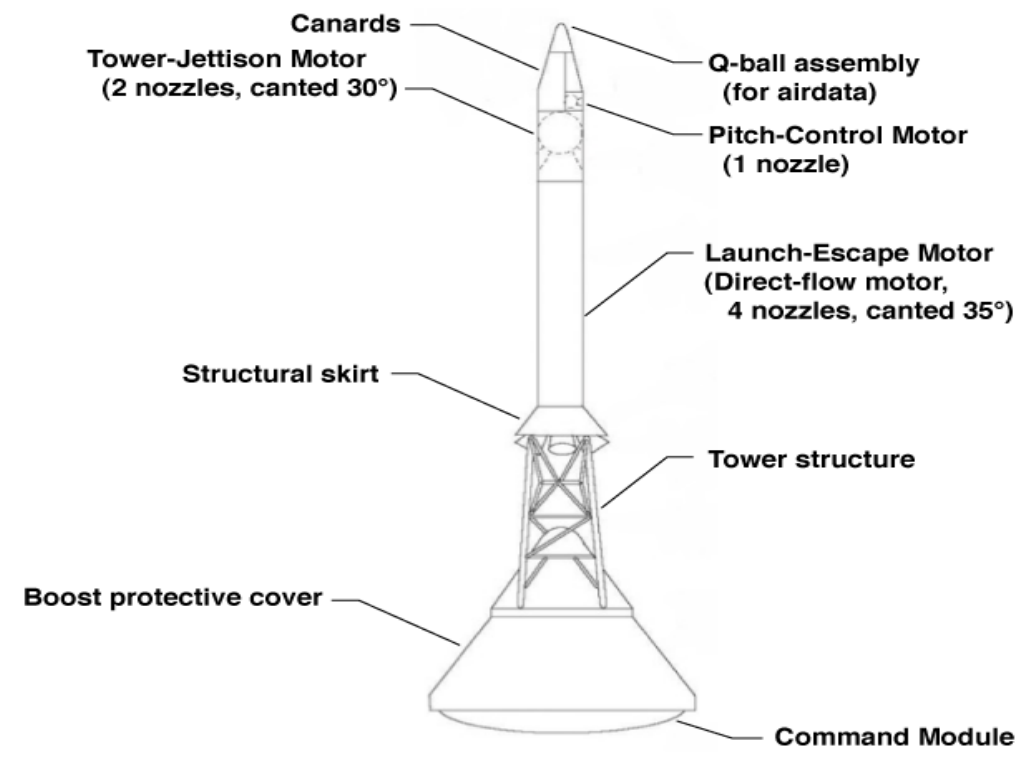

Figure 6. Apollo Command Module and LES.

The Apollo LES was designed to provide near-continuous escape capability for the astronauts during the climb to LEO, permitting a launch escape from the launch pad up through verification of the Saturn V second stage ignition. Since the Apollo LES had to be operationally capable of supporting the Apollo trajectory during Saturn V first stage operation, an Apollo LES flight-test program demanded LES demonstration during several critical points within this expected trajectory envelope. Unmanned qualification flights of the Apollo LES included two Pad Abort (PA) flights and six ascent flight tests. The six ascent flight tests included two Apollo flights (AS-101 and AS-102) to demonstrate Apollo LES jettison while under nominal launch conditions, and these missions were launched from the Kennedy Space Center (KSC), in Florida. The other four ascent flight tests were planned as aborted flights during the ascent, conducted on a booster designed to simulate the Saturn V first stage trajectory. These flights used the Apollo Little Joe II (LJ-II) launch vehicle, which were flight tested at the White Sands Missile Range (WSMR), in New Mexico. Figure 7 shows a photo of the Apollo LJ-II A-004 flight-test vehicle on the launch pad at WSMR. ${ }^{12}$ A summary of the Apollo LES flight-testing that was conducted is shown in table $1 .{ }^{11}$

Early in the Apollo LJ-II flight program a Qualification Test Vehicle (QTV) was also flight-tested to ensure that the LJ-II

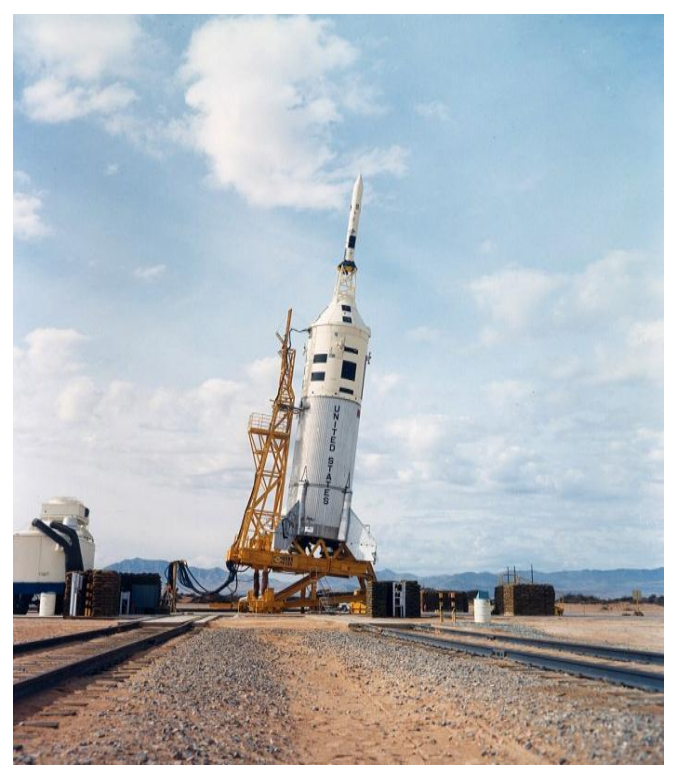

Figure 7. Photo of the Apollo LJ-II A-004 flight-test vehicle, on the launchpad at WSMR. 
booster was capable of delivering the Apollo LES to a possible escape/separation condition. The Apollo LJ-II QTV flight test was conducted on August 28, 1963 at WSMR, and included an inert LES. ${ }^{13}$

\section{E. Orion Abort Flight Test Program}

The Orion Abort Flight Test (AFT) Program was developed with the goal of conducting a series of flight tests in several launch abort scenarios to certify the Orion LAS is capable of delivering the astronauts aboard the Orion CM safely away from a failed booster. The Orion LAS flight-test vehicle (FTV) integration and operations effort was led by the NASA Dryden Flight Research Center (DFRC) Orion AFT team, at Edwards, California. ${ }^{14}$ The Orion AFT Program was managed by the Orion Flight Test Office (FTO) located at NASA JSC.

FTO preliminary flight-test plans for certification of the Orion LAS included two PA flights and four Ascent Abort (AA) flights, as noted in table $2 .{ }^{15}$ In addition to these six flights planned by the FTO, three additional high altitude flight tests were planned for KSC, and these are also noted in table $2 .{ }^{16}$ The CM architecture in earlier flights was to be a boilerplate CM provided by NASA, eventually progressing to an operational (productionlevel) CM produced by LM. The LAS architecture flight testing would develop in a similar fashion, with a flight-test specific system on earlier flights and eventually progressing to final flight tests with an operational LAS. The operational $\mathrm{CM}$ and LAS were to be identical, or nearly identical to the Ares I Orion CM and LAS architecture.

Two PA flights were identified to certify LAS capability in the event of a significant failure of the Ares I CLV before launch, or early in the first stage ascent. A launch escape system proved to be a life saver for the Soyuz T-10-1 crew on September 26, 1983 at the Baikonur Cosmodrome, when it was initiated on the launch pad after the booster caught fire just seconds before the planned launch. The PA-1 FTV was the first to successfully demonstrate the capability of the LAS, and was focused on this region. Figure 8 shows a photo of the PA-1 FTV with the PA-1 AFT launch team, about two weeks prior to launch day. ${ }^{17}$ Figure 9 shows a photo of the PA-1 FTV during its successful flight on May 6, 2010. ${ }^{18}$

All AA flights require the Abort Test Booster (ATB) to deliver the LAV to the appropriate test conditions, where a simulated abort would then be initiated. Separation test conditions for each AA flight, as noted in the "test description" column in table 2, were selected with a goal of demonstrating the LAV could abort from a failed booster during a critical ascent phase. Figure 10 shows the LAV attached to the ATB. The ATB was being designed to utilize the SR118 solid rocket motor, originally used as the first stage motor on the Peacekeeper intercontinental ballistic missile (ICBM), and categorized as surplus by the United States Air Force (USAF). Quantifying LAV separation performance would require simulating the Orion to Ares I CLV separation aerodynamics. Accordingly, the ATB outer mold line (OML) was required to replicate the Ares I CLV upper stage/Service Module. For this reason, the ATB design required an aeroshell structure to match the Ares I CLV OML since the motor case diameter of the SR118 is significantly less than the OML of the Ares I CLV upper stage.

Six flight tests were originally planned by the NASA FTO, and three additional Ares I flight tests were planned prior to human flight: Ares I-X, Ares I-Y, and Orion 1, as noted in table 2. Ares I-X was successfully flight tested on October 28, 2009, and demonstrated first stage operation, including an inert second stage propulsion system and

6

American Institute of Aeronautics and Astronautics 
inert LAS motors. The Ares I-Y flight objectives included the demonstration of a high altitude abort utilizing the LAS after a simulated second stage failure of the CLV. The Orion 1 flight plan would require a nominal jettison of the LAS, enabling the demonstration of an Orion CEV orbital insertion by the Ares I CLV. Orion 2 would be the first Ares I CLV launch with humans in the Orion CEV. ${ }^{16}$

Table 2. Flight-test description.

\begin{tabular}{|c|c|c|c|}
\hline Flight test & Test description & $\mathrm{CM}$ configuration & LAS configuration \\
\hline PA-1 & Abort from launch pad & NASA provided boilerplate & Flight-test specific \\
\hline AA-1 & Maximum dynamic pressure abort & NASA provided boilerplate & Flight-test specific \\
\hline PA-2 & $\begin{array}{l}\text { Abort from launch pad with flight-like } \\
\text { abort trajectory }\end{array}$ & $\begin{array}{l}\text { LM produced; more flight- } \\
\text { like structure }\end{array}$ & Operational \\
\hline AA-2 & Transonic abort & LM produced; operational & Operational \\
\hline AA-3 & $\begin{array}{l}\text { Off-nominal maximum dynamic pressure } \\
\text { abort }\end{array}$ & LM produced; operational & Operational \\
\hline AA-4 & High altitude abort & LM produced; operational & Operational \\
\hline Ares I-X & $\begin{array}{l}\text { High altitude first stage CLV } \\
\text { demonstration (second stage mass } \\
\text { simulator) }\end{array}$ & Mass simulator & $\begin{array}{l}\text { Inert, mass } \\
\text { simulator }\end{array}$ \\
\hline Ares I-Y & $\begin{array}{l}\text { High altitude LAV abort after CLV first } \\
\text { stage operation (prototype second stage } \\
\text { with J-2X mass simulator) }\end{array}$ & Prototype & $\begin{array}{l}\text { Functional, flight- } \\
\text { test specific }\end{array}$ \\
\hline Orion 1 & $\begin{array}{l}\text { Nominal flight, } \\
\text { orbital insertion of } \mathrm{CM}\end{array}$ & Operational & Operational \\
\hline
\end{tabular}

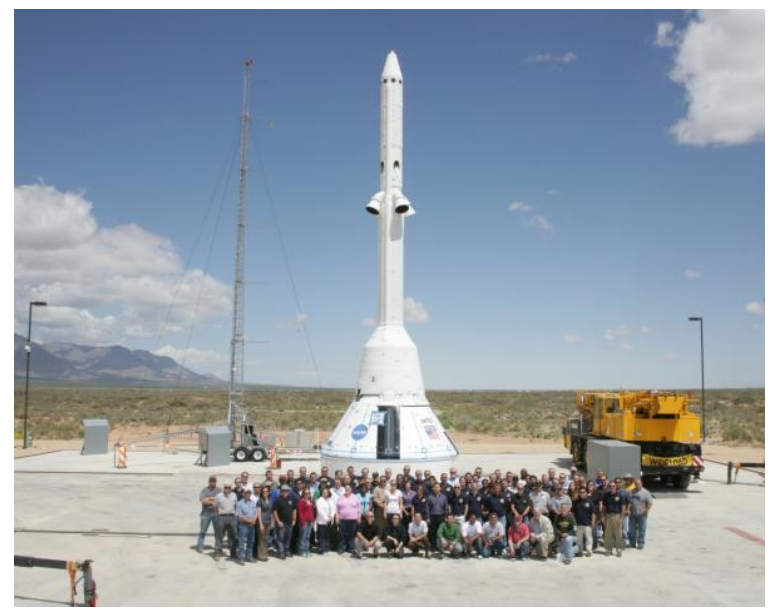

Figure 8. Photo of the PA-1 FTV with the PA-1 AFT launch team, April 2010.

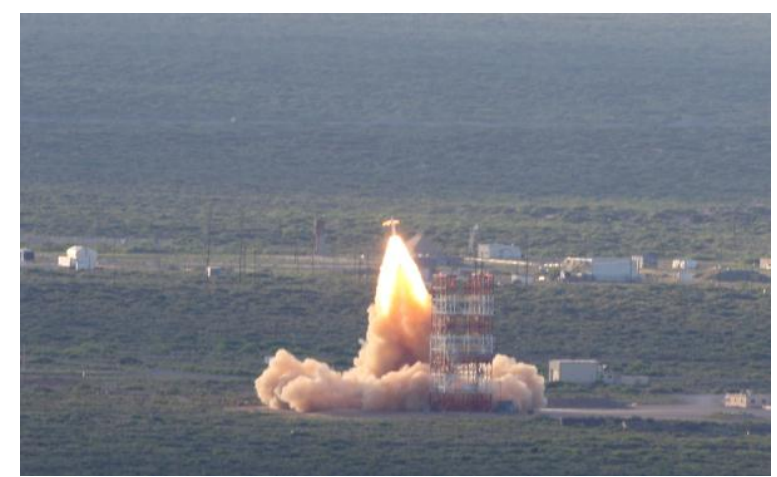

Figure 9. Photo of the PA-1 FTV during launch, May 6, 2010. 
In addition to the three LAS solid rocket motors and the SR118 solid rocket motor, the AA-1 FTV was to include a cold gas Reaction Control System (RCS) within the CM for roll control. Of critical importance to every flight was a better understanding of the CEV Parachute Assembly Subsystem (CPAS) performance, and the AA-1 FTV CM RCS would facilitate response characterization of the CPAS during AA-1 CM descent. Although the operational CM was designed to include a hot gas RCS, this propulsion subsystem was ultimately determined to be unnecessary in meeting the primary mission objectives of the Orion AFT program since a cold gas RCS could provide adequate control of the CM under the predicted flight conditions for the AA-1.

Each of the FTVs has greatly evolved over the program history, including revisions to the flight-test objectives and vehicle architecture, as well as the order in which these flights would be conducted. Elimination of some FTVs from the flight manifest was also necessary due to changes in project direction. For this reason, the reader should note that the details within table 2 represent one of the earliest flight-test manifests, and has been significantly revised. Future Orion flight-test plans are still being discussed and evaluated given the ongoing operational evolution of the Orion spacecraft.

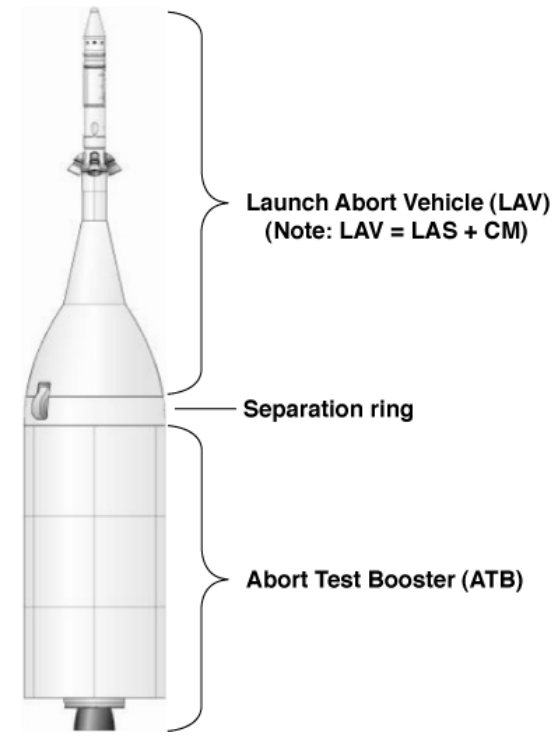

Figure 10. View of a typical AA FTV, with LAV, Sep Ring, and ATB.

\section{Flight-Test Vehicle Propulsion Overview}

Each of the five propulsive subsystems originally planned for use on at least one of the Orion FTVs is discussed below. This includes a brief overview of the LAS AM, LAS ACM, LAS JM, CM RCS, and ATB SR118.

\section{A. LAS AM Overview}

The LAS AM provides the thrust force necessary to propel the LAV safely away from a failed booster. Propulsion performance, or acceleration of the LAV, is properly balanced between a desire for the quickest possible abort capability and the human tolerance for acceleration. Motor performance requirements were also driven by the possibility of a potential abort at any point during pre-launch and ascent, as noted earlier. The LAS AM is designed and manufactured by Alliant Techsystems, Inc. (ATK) in Utah, which is part of the ATK Aerospace Systems group. The ATK corporate headquarters is based in Arlington, Virginia.

The LAS AM is a single solid rocket motor with an overall length of 209 inches and a case outside diameter of 36 inches. The motor has an architecture that includes four reverse-flow nozzles, a design driven by the requirement to minimize the severity of the plume impingement and acoustic environment on the Orion CM. This architecture also negated the necessity of an additional structure to extend the LAS from the CM, as was done with the Apollo LES. The reverse flow nozzles are canted 25 degrees from the LAS centerline, resulting in an unconventional total flow turning angle of 155 degrees. Nozzle throats for the LAS AM are preselected based on the desired LAV thrust offset for each individual mission weight requirement. The four LAS AM nozzles are combined through a single component which is called the LAS AM manifold, and is responsible for turning and distributing the hot flow-field to the nozzles. The PA-1 LAS AM has a nominal maximum thrust of almost 500,000 lbf, and has an action time of almost 7 seconds. Figure 11 shows an external view of the LAS AM.

The LAS AM is a high performance solid rocket motor, which drives the design requirements for the propellant constituents and grain configuration. The LAS AM utilizes a high burn rate propellant with a hydroxyl-terminated polybutadiene (HTPB) binder system, and it is cast into a high surface area grain configuration. The propellant is cast into a high performance carbon fiber composite case with a Kevlar ${ }^{\circledR}$-filled ethylene propylene diene monomer (EPDM) case insulator. The LAS AM case serves as the pressure chamber for the LAS AM as well as the primary structure for the LAS.

The LAS AM manifold is designed such that it converges and stabilizes the incoming hot flow field, and distributes the hot gases to the nozzles. Ultimately, the manifold is responsible for turning the entire flow field through 155 degrees and distributing it to the nozzles as efficiently as possible. The PA-1 LAS AM manifold was made of 4340 steel, and had several electron beam welded joints. The production LAS AM was redesigned to utilize 
a $6 \mathrm{Al}-4 \mathrm{~V}$ titanium manifold, primarily to reduce weight. Figure 12 is a photo of the LAS AM manifold during hydroproof testing at ATK, ${ }^{19}$ and this particular manifold was later used for ATK's first full scale static fire test of the LAS AM.

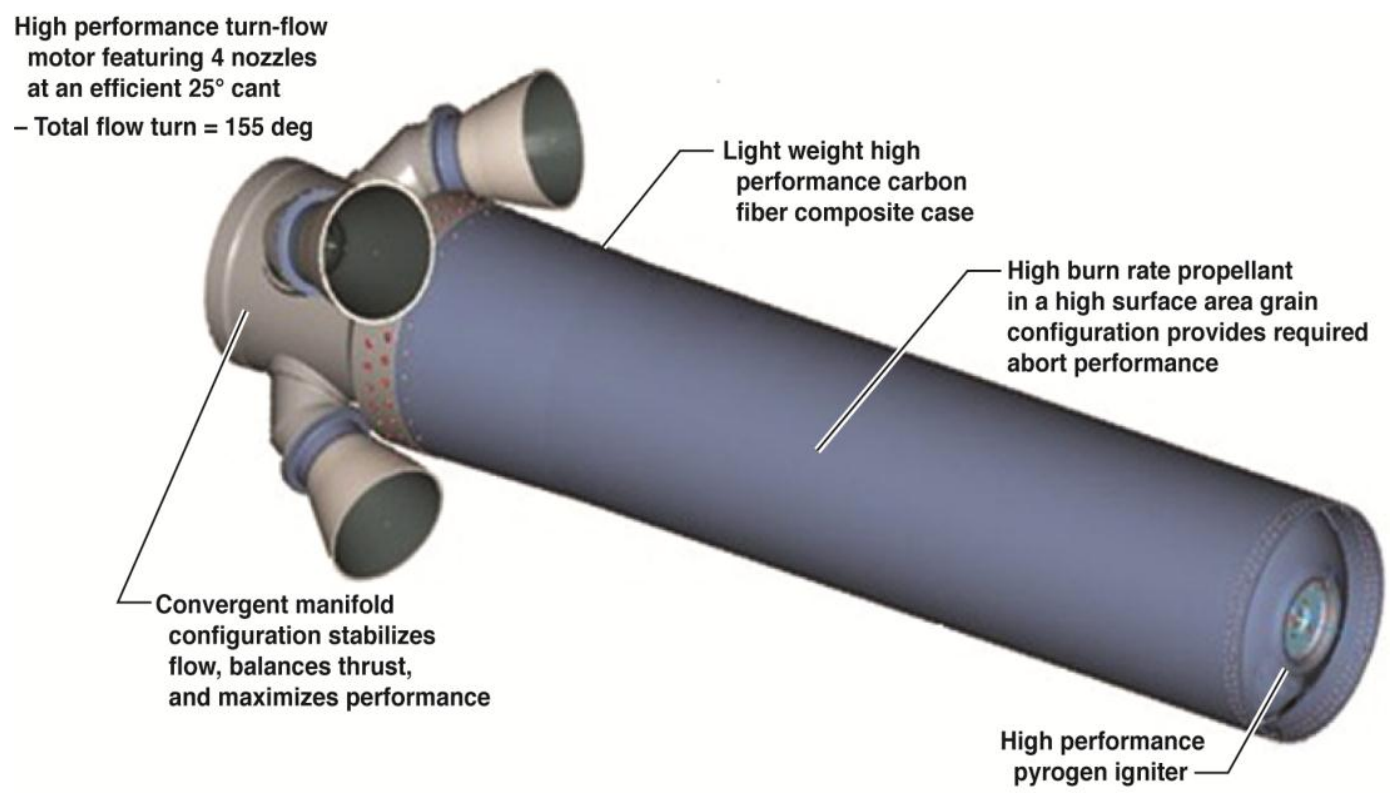

Figure 11. External view of the PA-1 LAS AM.

Minimal ignition delay is also a critical requirement for this motor, which resulted in the design of a high performing pyrogen igniter that is relatively large for the size of the motor. The igniter is initiated by redundant through-bulkhead initiators (TBIs), which transfer energy to a boron potassium nitrate $\left(\mathrm{BKNO}_{3}\right)$ pellet bag, which then transfers energy to the pyrogen propellant grain. The pyrogen igniter has a carbon fiber composite case with several small radial ports and one large axial port, all designed to provide a high mass flow of hot gases quickly and uniformly from the igniter to the LAS AM main propellant grain surface.

The ATK team met several significant milestones prior to their successful demonstration of the LAS AM performance for the PA-1 FTV. Major successes started with ATK's independent research and development (IR\&D) efforts which led to three subscale reverse flow tractor motor static test firings in 2005 and 2006. These successful ATK funded IR\&D efforts helped guide the design and requirements for three subsequent tests under the LAS Abort Motor program, which included Subscale Test \#1 (SST-1), Subscale Test \#2 (SST-2), and the full scale Static Test \#1 (ST-1). Key attributes of each of these tests are noted in table 3 .

Figure 13 shows a photograph of ATK personnel during calibration of the new LAS AM static fire test stand, with a full-scale inert LAS $\mathrm{AM}^{20}{ }^{20}$ Figure 14 shows a photograph of the successful LAS AM ST-1 conducted on November $20,2008 .^{21}$ The SST-1, SST-2, and ST-1 motors were all static fire tested at the ATK Promontory facility in Utah.

The power and reverse-flow architecture of the LAS AM make this motor a truly remarkable design achievement. The ATK-Utah team demonstrated the soundness of their design through several static fire test milestones as noted above, and significantly built confidence in the LAS AM design as the Orion Project team

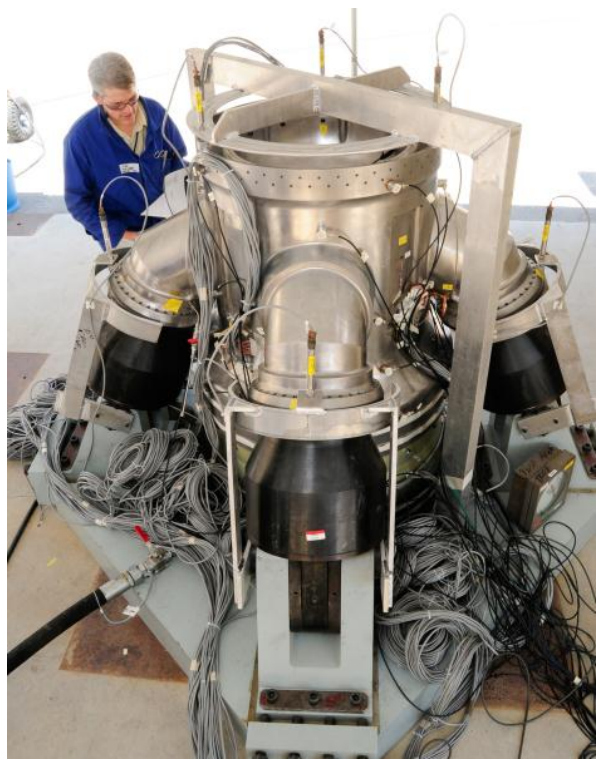

Figure 12. Photo of the LAS AM manifold during hydroproof testing at ATK. progressed toward PA-1. 
Table 3. LAS AM static fire test milestones.

\begin{tabular}{|c|c|c|c|}
\hline & SST-1 & SST-2 & ST-1 \\
\hline $\begin{array}{l}\text { Static fire } \\
\text { test date }\end{array}$ & $\begin{array}{c}\text { June } 26, \\
2007\end{array}$ & $\begin{array}{c}\text { August 10, } \\
2007\end{array}$ & $\begin{array}{c}\text { November } 20, \\
2008 \\
\end{array}$ \\
\hline Description & \multicolumn{2}{|c|}{$\begin{array}{l}\text { Subscale test series: } \\
-\quad 1 / 4 \text {-scale of the } \\
\text { geometry } \\
-\quad 1 / 25 \text {-scale of the } \\
\text { overall thrust }\end{array}$} & First full-scale test \\
\hline $\begin{array}{c}\text { Test } \\
\text { configuration }\end{array}$ & \multicolumn{2}{|c|}{ Horizontal } & $\begin{array}{c}\text { Vertical, upside- } \\
\text { down }\end{array}$ \\
\hline $\begin{array}{c}\text { Nozzle } \\
\text { configuration }\end{array}$ & \multicolumn{2}{|c|}{$\begin{array}{ll}\text { - } & \text { Two reverse flow } \\
\text { nozzles } \\
\text { - } & 180 \text { degrees apart } \\
\text { - } & \text { Canted } 25 \text { degrees }\end{array}$} & $\begin{array}{l}\text { - Four reverse } \\
\text { flow nozzles } \\
\text { - } 90 \text { degrees apart } \\
\text { - Canted } 25 \\
\text { degrees }\end{array}$ \\
\hline
\end{tabular}

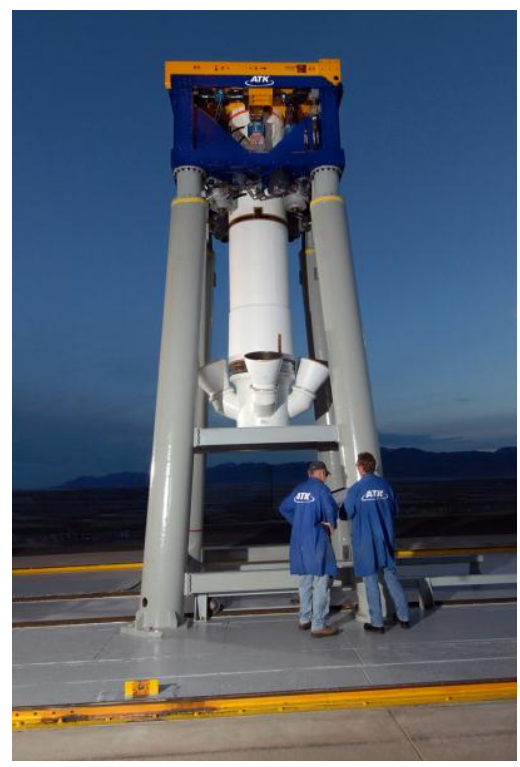

Figure 13. Photo of the full-scale LAS AM static fire test stand.

The LAS ACM provides pitch and yaw control to optimize the LAV abort trajectory, and is utilized from the moment an abort has been commanded, up until the LAS is jettisoned from the Orion CM. Through the use of 360 degree proportional thrust vectoring and proportional thrust control, the ACM orients the LAV to attitudes commanded by the Orion CM. Immediately after ignition, the ACM is used for Orion LAV directional control during ascent vehicle separation, and also provides a high level of thrust in these first few seconds of operation to stabilize the LAV during abort motor operation. Motor operation continues in a lower level of thrust with pitch-over and reorientation of the Orion LAV into a CM heat-shield forward attitude. Finally, the ACM stabilizes the LAV in this attitude in preparation for, and through LAS

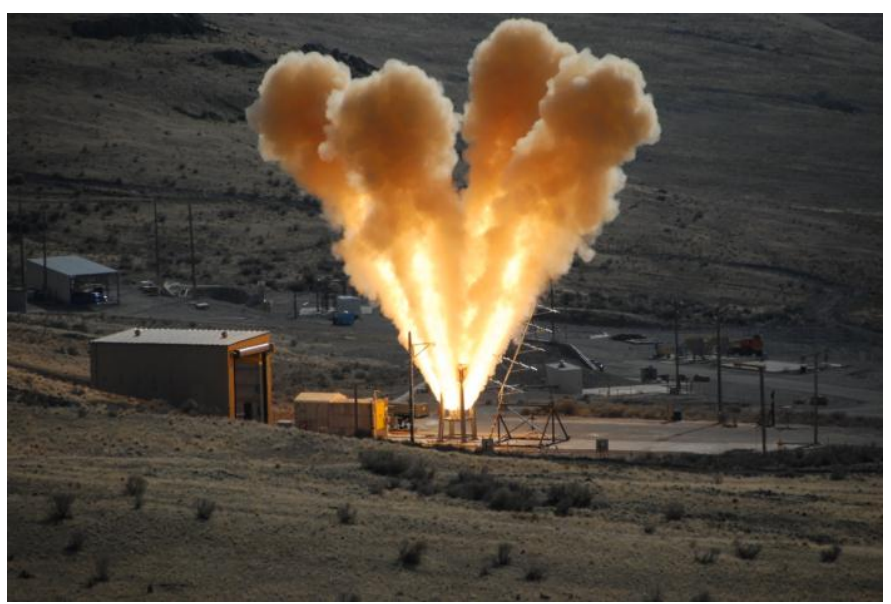

Figure 14. Photo of the full-scale LAS AM ST-1, during static fire testing. jettison from the Orion CM, followed by parachute deployment. The LAS ACM is designed and manufactured by ATK, in Elkton Maryland, which is part of the ATK Missile Products group.

The LAS ACM is a single solid rocket motor with an overall length of 62 inches and a case outside diameter of 32 inches. The motor has a design that includes eight nozzles equally spaced around the motor circumference. The mass flow rate of combustion products through each of these nozzles is controlled by a proportionally commanded pintle valve, where the throat area of each nozzle is varied as needed. The LAS ACM architecture also includes two independent controllers (one of which is redundant) to control operation of the eight pintle valves through the actuator system, with an arbiter board for redundancy management between controllers. This permits the ACM to modulate total thrust in any direction perpendicular to the primary axis of the LAS while maintaining the proper total open throat area to sustain the appropriate chamber pressure of the motor. A lithium-ion battery assembly provides power for the control system, including 28-volt and 140-volt batteries, each with a redundant backup. The PA-1 LAS ACM has a maximum thrust of 7,000 lbf, and it has a maximum action time of 35 seconds. Figure 15 shows an external view of the ACM.

The LAS ACM has performance characteristics that are significantly unique for a typical solid rocket motor. The propellant consists of a carboxyl-terminated polybutadiene (CTPB) binder system, which was chosen based on its compatibility with the ACM valve material components, as well as its well-characterized ballistic properties. The ACM case and forward closure are both made of ATK-heritage D6AC steel, both with Kevlar ${ }^{\circledR}$-filled EPDM 
internal insulation. The PA-1 ACM utilized a high performing pyrogen igniter, which was mounted in the center of the ACM forward closure. The pyrogen igniter is initiated by redundant TBIs and a $\mathrm{BKNO}_{3}$ pellet basket, and it has a 4340 steel case with several exhaust ports.

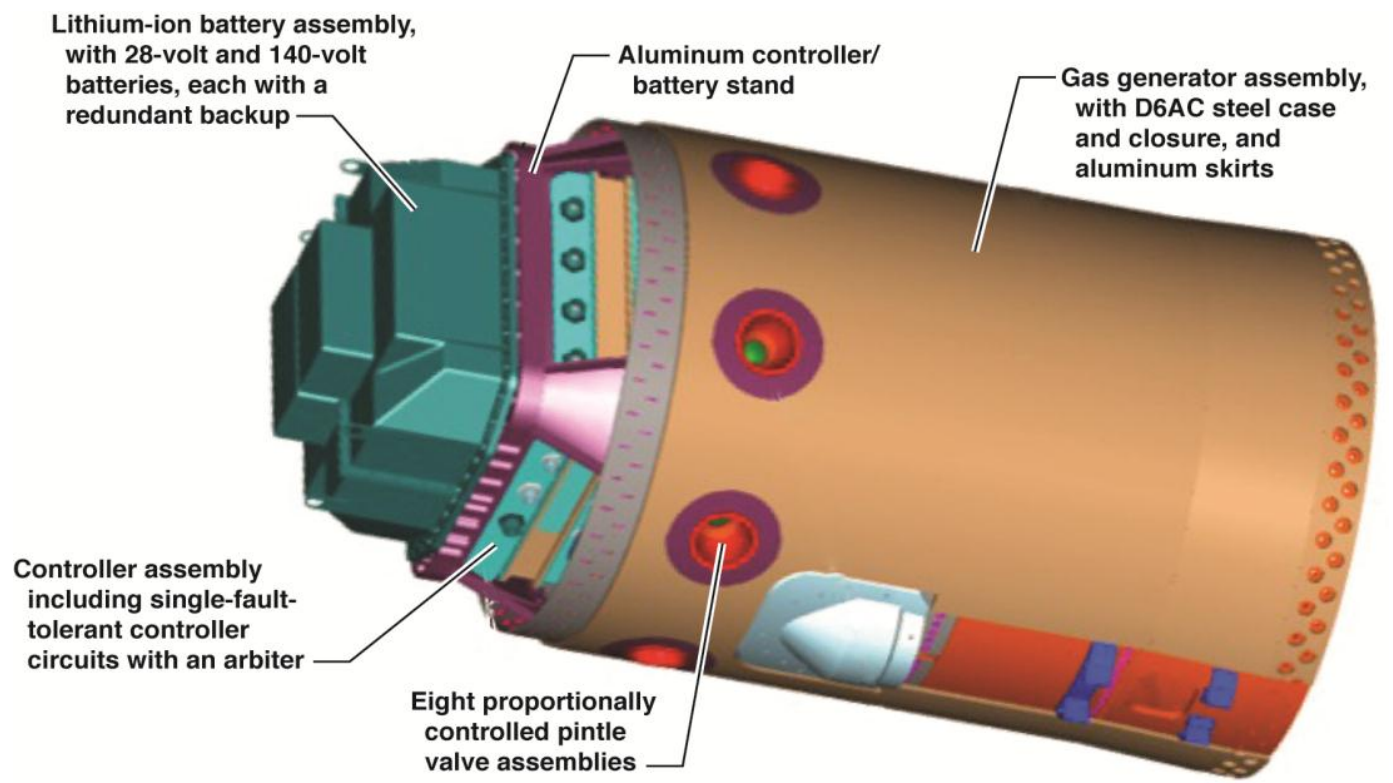

Figure 15. External view of the LAS ACM.

Eight valve assemblies are mated with the ACM forward closure, each with components made of several hightemperature compatible materials internal to the valve. One of the most challenging regions of this design was in fact the valve assembly, with a requirement for structural integrity while under severe mechanical and thermal loads. For this reason, the valve components under the harshest environment were made of carbon/carbon-silicon carbide. Each of these valves is driven by a redundant Moog actuator, which is controlled by the controller assembly.

The ATK-Elkton team successfully completed numerous significant milestones that resulted in a successful PA-1 flight test. These efforts culminated in several static hot-fire tests that advanced the technology of a controllable solid rocket motor. There were seven subscale static fire tests and two full-scale static hot-fire tests prior to PA-1. All of the subscale static fire tests were focused on maturing the technology and capability of the valve assembly. The subscale tests in this high thrust (HT) test series utilized full-scale valve assemblies with a subscale solid propellant loading, and progressed from a heavy weight valve assembly to a more flight-like valve assembly. The first two HT tests were conducted in 2003 and 2006, under ATK IR\&D funding to demonstrate this technology could be advanced. The third HT test was deleted from the test series. ATK continued static fire testing in the HT series under the LAS ACM program, starting with HT-4 and concluding with HT-8A. Key attributes of each of these test milestones are noted in table 4 .

Table 4. LAS ACM subscale static fire test milestones.

\begin{tabular}{l|ccccc}
\cline { 2 - 6 } & HT-4 & HT-5 & HT-6 & HT-7 & HT-8A \\
\hline $\begin{array}{l}\text { Static fire test } \\
\text { date }\end{array}$ & $\begin{array}{c}\text { October 31, } \\
2007\end{array}$ & $\begin{array}{c}\text { January 31, } \\
2008\end{array}$ & $\begin{array}{c}\text { January 14, } \\
2009\end{array}$ & $\begin{array}{c}\text { April 9, } \\
2008\end{array}$ & $\begin{array}{c}\text { March 31, } \\
2009\end{array}$ \\
$\begin{array}{l}\text { Number of } \\
\text { valves }\end{array}$ & 1 & 1 & 1 & 2 & 1 \\
Burn time & $\sim 9 \mathrm{~s}$ & $\sim 27 \mathrm{~s}$ & $\sim 27 \mathrm{~s}$ & $\sim 8 \mathrm{~s}$ & $\sim 13 \mathrm{~s}$ \\
\hline \hline
\end{tabular}


As noted earlier, the ACM valve design proved challenging to optimize, and evolved during the HT-series subscale test and analysis phase. This is an excellent example of why research testing is required, to complement the design analysis phase. Ultimately, the HT series tests built confidence in the valve assembly and controller hardware, and enabled a progression to full scale ACM static fire testing.

There were two full-scale ACM demonstration motor (DM) static fire tests prior to the PA-1 flight test. Both the DM-1 and DM-2 were flight-weight motors, utilizing a full propellant loading and a full set of eight pintle valve assemblies operating with a control system. The ACM DM-1 was static fire tested on December 15, 2009, and the ACM DM-2 was static fire tested on March 17, 2010. The ACM DM-1 and DM-2 tests had performance characteristics closer to what was predicted for the PA-1 ACM, and both were primary verification events for the ACM program, proving compliance with requirements. Figure 16 shows a photo of the ACM DM-2 during static fire testing. ${ }^{22}$ Like all of the HT series static fire tests, both the DM-1 and DM-2 were static fire tested at ATK-Elkton.

The LAS ACM proved to require advanced technological capabilities that were greater than anticipated, making the ACM program development very challenging. The ATK-Elkton team continually proved to be up to the challenge, and successfully matured the ACM in preparation for the PA-1 flight test.

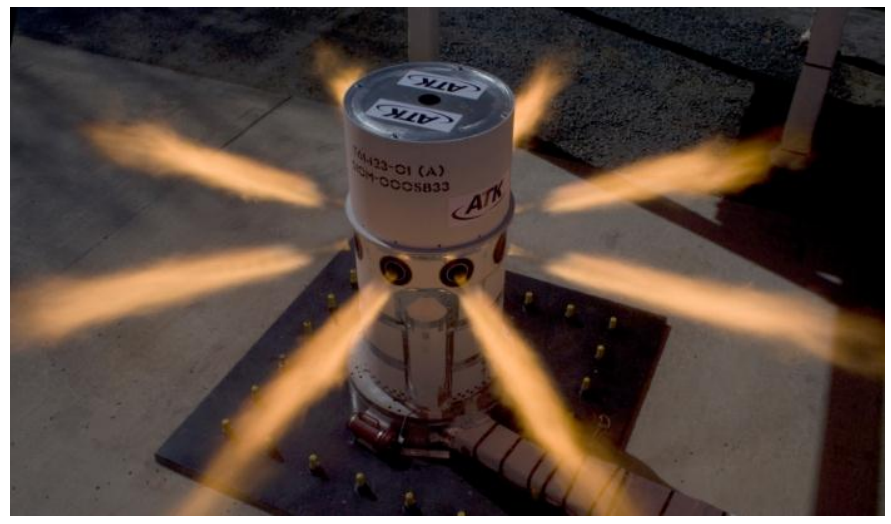

Figure 16. Photo of the LAS ACM DM-2 during static fire testing.

\section{LAS JM Overview}

The LAS JM provides the thrust force required to jettison the LAS from the Orion CM, in both the abort and nominal flight scenarios. In an abort scenario the LAS JM is utilized after the LAS AM and ACM have performed their required functions, and is used to jettison the LAS from the Orion CM in preparation for parachute deployment. In a nominal flight scenario, where astronauts are not required to abort their flight plan, the LAS JM was designed to provide the thrust required to jettison the fully loaded LAS (with unused LAS AM and LAS ACM propellant) from the Orion CM, occurring concurrently with the Ares I CLV propelling forward under second stage operation. Therefore, the LAS JM carries the unique responsibility of operating on every flight, whether an aborted or a nominal flight. The LAS JM is designed and manufactured by Aerojet in Sacramento, California. The AerojetGeneral Corporate headquarters is also in Sacramento, California.

The LAS JM is a single solid rocket motor with an overall length of 50 inches and a case outside diameter of 32 inches. The motor has an architecture that includes four scarfed nozzles that are each canted 35 degrees from the primary axis of the LAS. The JM architecture also includes three large nozzle throats and one small nozzle throat, designed to offset the desired thrust vector of the overall motor. This design requirement was driven by the nominal flight scenario, to clear the LAS from the Ares I CLV flight path. The PA-1 LAS JM has a maximum nominal thrust of over 40,000 lbf, and it has an action time of almost 2 seconds. Figure 17 shows an external view of the LAS JM.

The LAS JM is a relatively high thrust motor for its short action time, a thrust profile which was driven by the requirement to quickly jettison the LAS from the Orion CM. The propellant is cast into a high surface area grain configuration, providing the required high initial burn surface area. The LAS JM propellant was partially chosen based on its well-characterized properties, and was developed to be similar to previous Aerojet propellant formulations, and it utilizes an HTPB binder system. The JM case and closure are both made of 6Al-4V titanium, and both have a Kevlar ${ }^{\circledR}$-filled EPDM internal insulation. The shroud assembly is in a clamshell configuration with structural ribs, and is also made of $6 \mathrm{Al}-4 \mathrm{~V}$ titanium. The nozzle assemblies utilize a $17-4$ stainless steel housing with Kevlar $^{\circledR}$-filled EPDM insulation and an ATJ graphite throat insert. A pyrogen igniter is utilized, and is ignited with a $\mathrm{BKNO}_{3}$ ignition charge, and redundant TBIs.

The Aerojet team met several significant milestones prior to their successful demonstration of the LAS JM performance for the PA-1 FTV. Major successes started with three subscale ballistic test evaluation system (BATES) test motors which were all static fired in October 2007. Key attributes of each of these tests are noted in table 5. The LAS JM BATES series tests built confidence in the igniter and nozzle performance capability, and enabled the progression to full-scale JM static fire testing. 
There were two full-scale JM DM static fire tests prior to the PA-1 flight test, and the configuration of both the DM-1 and DM-2 were flight-like. The LAS JM DM-1 was static fire tested on March 27, 2008, and the DM-2 was static fire tested on July 17, 2008. The JM DM-1 and DM-2 tests were both primary verification events for the LAS JM program, proving compliance with requirements. Figure 18 shows a photo of the JM DM-2 during static fire testing. ${ }^{23}$ Like all of the BATES series static fire tests, both the DM-1 and DM-2 were static fire tested at Aerojet, in Sacramento, California.

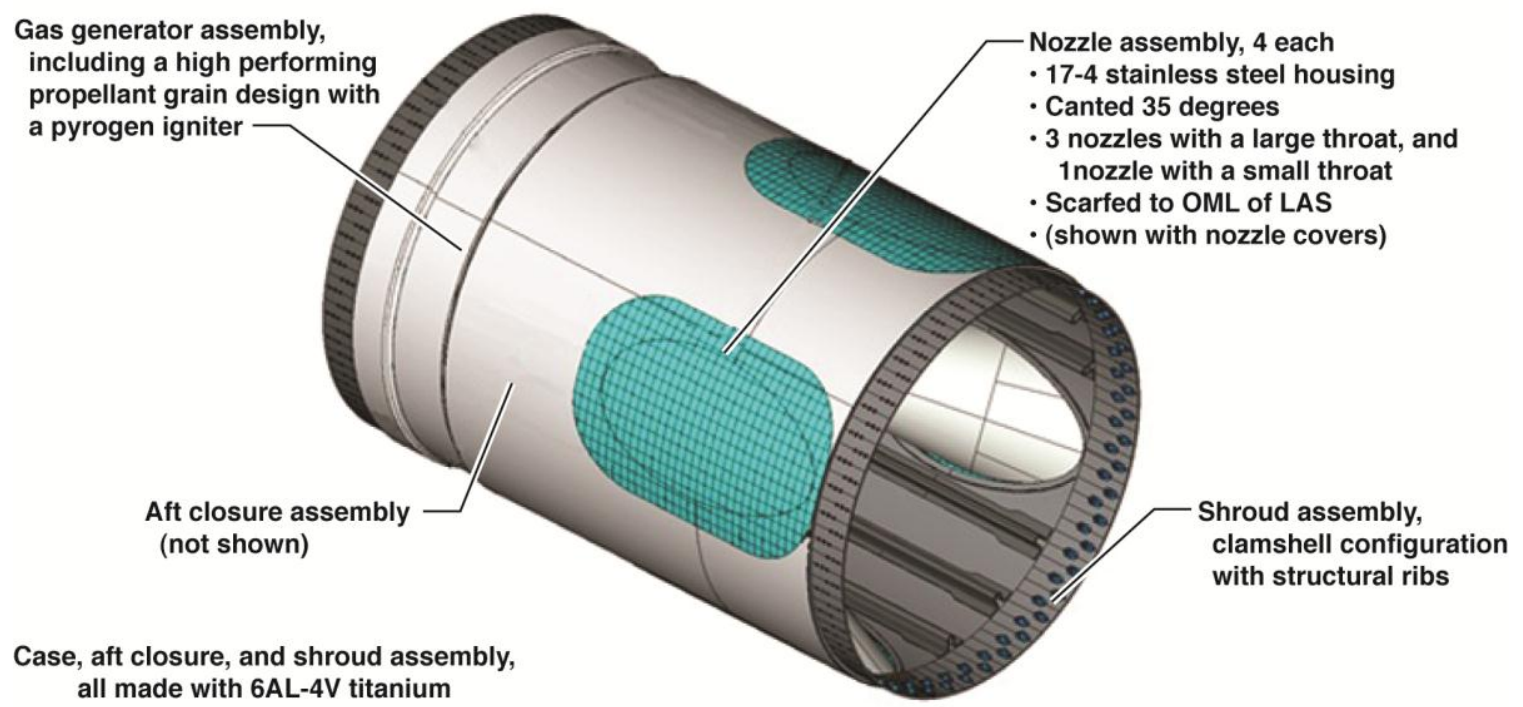

Figure 17. External view of the PA-1 LAS JM.

Table 5. LAS JM BATES test milestones.

\begin{tabular}{|c|c|c|c|}
\hline & BATES-1 & BATES-2 & BATES-3 \\
\hline $\begin{array}{l}\text { Static fire test } \\
\text { date }\end{array}$ & October 2, 2007 & October 9, 2007 & $\begin{array}{c}\text { October } 17, \\
2007\end{array}$ \\
\hline $\begin{array}{l}\text { Top-level } \\
\text { description }\end{array}$ & $\begin{array}{l}\text { Igniter assembly } \\
\text { test in free } \\
\text { volume } \\
\text { simulator }\end{array}$ & $\begin{array}{l}\text { Axial nozzle } \\
\text { assembly test }\end{array}$ & $\begin{array}{l}\text { Canted and } \\
\text { scarfed nozzle } \\
\text { assembly test }\end{array}$ \\
\hline $\begin{array}{l}\text { Test } \\
\text { configuration } \\
\text { details }\end{array}$ & $\begin{array}{l}\text { - Full-scale } \\
\text { igniter } \\
\text { - Open BATES } \\
\text { chamber } \\
\text { - No nozzle }\end{array}$ & $\begin{array}{l}\text { - Sub-scale } \\
\text { igniter } \\
\text { - BATES } \\
\text { chamber with } \\
\sim 1 / 4 \text { flight } \\
\text { mass } \\
\text { propellant } \\
\text { - Single nozzle, } \\
\text { axial, with } \\
\text { flight-like } \\
\text { throat (large) }\end{array}$ & $\begin{array}{l}\text { - Sub-scale } \\
\text { igniter } \\
\text { - BATES } \\
\text { chamber with } \\
\text { 1/4 flight } \\
\text { mass } \\
\text { propellant } \\
\text { - Single nozzle, } \\
\text { canted and } \\
\text { scarfed, with } \\
\text { flight-like } \\
\text { throat (large) }\end{array}$ \\
\hline
\end{tabular}

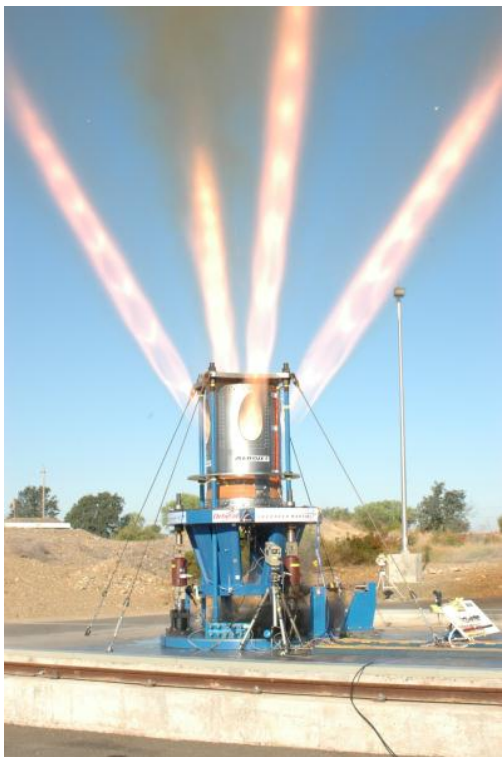

Figure 18. Photo of the LAS JM DM-2 static fire test.

The Aerojet team led the Orion project with the first full-scale static fire test of a LAS motor, the LAS JM DM-1. With this, the Aerojet team also helped advance the momentum of successful milestones toward the PA-1 flight test, and boosted the Orion team's confidence in the LAS JM design. 


\section{CM RCS Overview}

The Orion CM RCS was planned for use on the AA-1 flight test, a flight that was originally intended to demonstrate the performance of the LAS while the FTV is traveling through a maximum dynamic pressure condition. For AA-1, the CM RCS was required to induce a roll torque to determine the response of the CPAS after the main chutes were deployed, and then to operate a roll control algorithm to position the CM properly for landing. The RCS was also to provide rate damping, as needed. After RCS operations were complete, the propellant would be vented through non-propulsive vents. The design, development, testing, and construction of the AA-1 CM RCS was led by the NASA Glenn Research Center (GRC), in Cleveland Ohio. NASA DFRC was a partner to the NASA GRC team in the RCS integration activities within the AA-1 CM.

The CM RCS is a cold gas propulsion system using gaseous nitrogen $\left(\mathrm{GN}_{2}\right)$ propellant. For the purposes of AA-1, the RCS would provide thrust in one axis (roll), although it has the capability to expand to all three axes of roll, pitch, and yaw. Figure 19 is a schematic representation of the RCS. The RCS consists of five types of subassemblies: the tank assemblies, pressure reducing assembly (PRA), thruster assemblies, service valve assembly, and vent assembly. The RCS utilizes approximately 400 pounds of $\mathrm{GN}_{2}$, and is stored (at 3,500 psia and $70^{\circ} \mathrm{F}$ ) in four propellant tanks that would be distributed throughout the CM, each with a 180 -liter capacity. The PRA receives high-pressure $\mathrm{GN}_{2}$ from the propellant tank assemblies, reduces the pressure to approximately 600 psia, and distributes the regulated $\mathrm{GN}_{2}$ to the thrusters. The PRA consists of a solenoid-operated isolation valve, a pressurereducing regulator, a relief valve, and two pyrotechnically operated vent valves (used to depressurize the RCS after operations are completed). The RCS utilized two thruster assemblies for roll control, both of which would be mounted on one of the CM panels. Each thruster assembly consists of a solenoid-operated thruster valve, thruster, and mounting structure. Pressurization and depressurization of the RCS would be accomplished through the service valve assembly, via two service (fill/drain) valves accessed from the exterior. One service valve provides access to the high-pressure side, whereas the other provides access to the low-pressure side. The vent assembly would consist of two non-propulsive vents. Propellant lines connect the various subassemblies together, and pressure and temperature transducers are used for health monitoring in every isolated segment of the system. Figure 20 shows the layout of the RCS in the CM. The total RCS wet mass was designed to be no greater than $2,910 \mathrm{lbm}$.

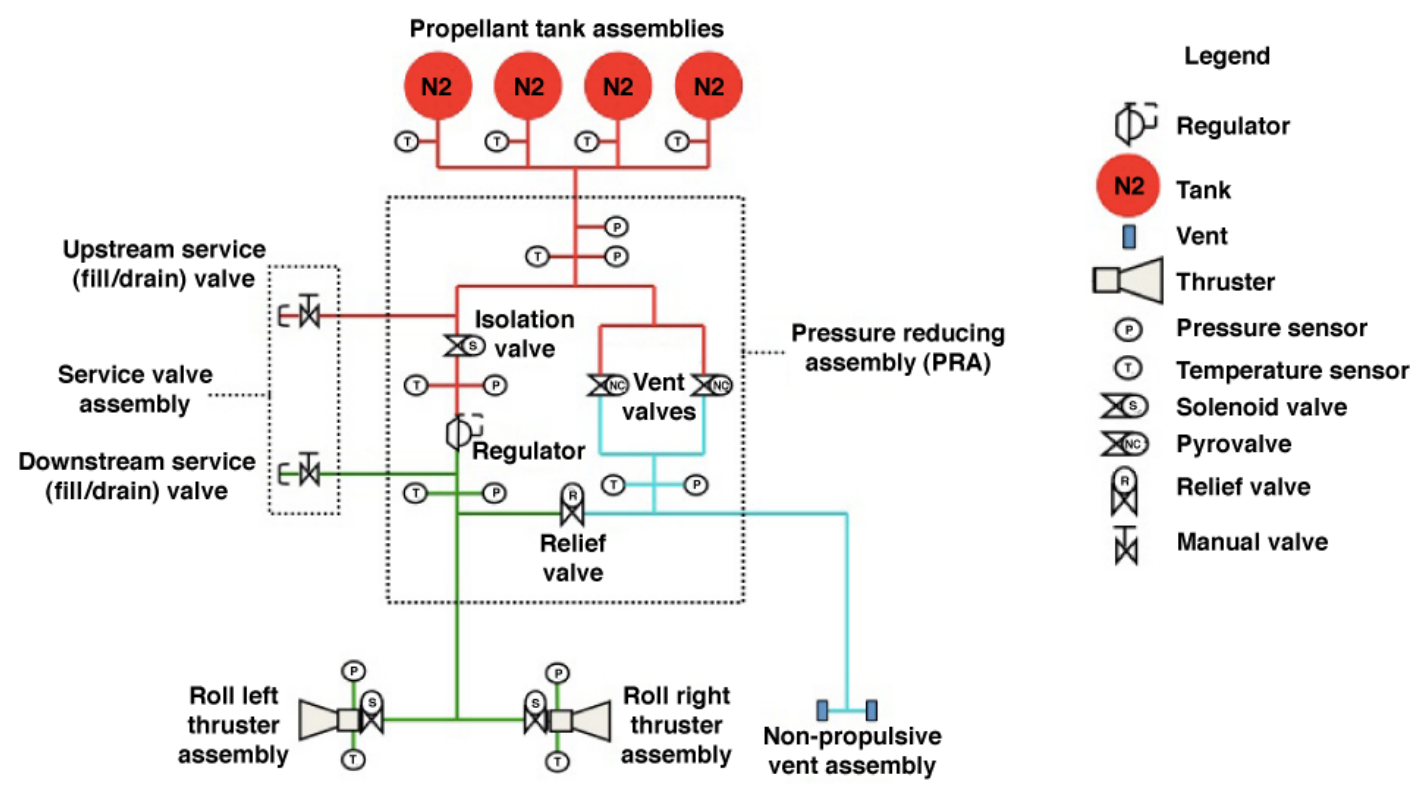

Figure 19. RCS schematic.

Each RCS thruster is capable of delivering a minimum thrust level of $150 \mathrm{lbf}$ (at 450 psia chamber pressure), with both thrusters oriented for CM roll control. The thrusters have simple conical nozzles with scarfed nozzle extensions, so that the exit planes would match the contour of the CM exterior. Developmental thruster testing was conducted to better understand the effect of the scarfed nozzle extensions on performance.

The RCS was designed to provide thrust during five operational phases, as shown in table 6 . The time column in the table equates time $=0$ to the first activation of the RCS.

The propellant tanks are composite overwrapped pressure vessels (COPVs). Damage tolerance testing was conducted at the NASA White Sands Test Facility (Las Cruces, New Mexico) to verify that they complied with the

14

American Institute of Aeronautics and Astronautics 
aerospace COPV standard (ANSI/AIAA S-081A-2006). ${ }^{24}$ Two burst tests were conducted, and in both cases the COPV burst limit far exceeded the requirements of S-081A.

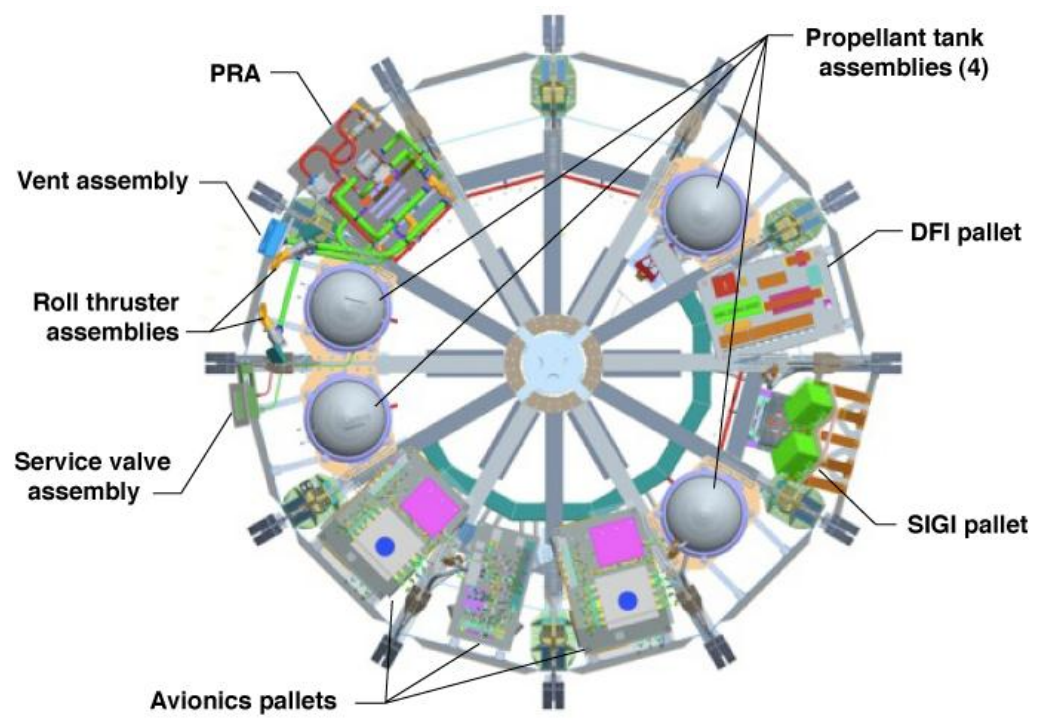

Figure 20. Top view of the CM showing the RCS layout.

Table 6. AA-1 CM RCS operation.

\begin{tabular}{|c|c|c|c|c|c|}
\hline Phase & RCS function & Time*, s & Altitude, $\mathrm{ft}$ & Pulse type & $\begin{array}{l}\text { Firing } \\
\text { time, } s\end{array}$ \\
\hline \multirow[b]{2}{*}{1} & & $0-1$ & $34,750-34,550$ & Steady-state & 0.8 \\
\hline & $\begin{array}{l}\text { Rate damping after } \\
\text { drogue chute deployment }\end{array}$ & $2-70$ & $34,550-16,675$ & $\begin{array}{l}\text { (34) } 0.4 \text { s pulses @ } \\
20 \% \text { duty cycle }\end{array}$ & 13.6 \\
\hline 2 & Rate damping & $177-178$ & $9,200-9,130$ & Steady-state & 2.5 \\
\hline \multirow{2}{*}{3} & Induced roll torque & $184-196$ & $9,000-8,680$ & Steady-state & 11.4 \\
\hline & objective) & $196-202$ & $8,675-8,520$ & $\begin{array}{l}\text { (5) } 0.4 \text { s pulses @ } \\
36 \% \text { duty cycle }\end{array}$ & 2.0 \\
\hline 4 & Rate damping & $202-205$ & $8,500-8,430$ & Steady-state & 2.5 \\
\hline \multirow[b]{2}{*}{5} & & $221-223$ & $8,000-7,960$ & Steady-state & 1.7 \\
\hline & Roll control algorithm & $223-268$ & $7,945-6,700$ & $\begin{array}{l}\text { (86)0.4 s pulses @ } \\
75 \% \text { duty cycle }\end{array}$ & 34.4 \\
\hline
\end{tabular}

$*$ time $=0$ corresponds to RCS activation at an altitude of 35,000 ft, approximately 80 seconds after launch.

15

American Institute of Aeronautics and Astronautics 
A developmental testbed of the RCS was used to characterize the fluid and thermal behavior of the system during pressurization, RCS operation, and post-operation venting. Figures 21 and 22 show photos of the RCS developmental testbed, which utilized the spare units of the flight hardware and instrumentation. Two complete sets of tests (pressurization, operation, and venting) were conducted with the RCS developmental testbed. In general, the test results agreed with the trends in the fluid/thermal modeling.

The purpose of the AA-1 CM RCS was to provide thrust in the roll axis in order to determine the response of the CPAS, provide CM rate damping, and position the CM for landing. NASA GRC led the design effort of the CM RCS, completing much of the detailed design and receiving the bulk of the flight components. Planning for manufacturing, assembly, verification testing, and integration would have been addressed at the RCS critical design review. The CM RCS development effort was progressing through all major milestones on schedule prior to the elimination of the AA-1 FTV from the flight manifest.

\section{E. ATB SR118 Overview}

The SR118 solid rocket motor is planned to be used as the booster for all AA FTVs with the ATB, and was selected to provide the required thrust force to simulate an ascent of the Orion spacecraft on the Ares I CLV. During ascent the ATB SR118 will deliver the Orion LAV to the appropriate test conditions for an abort, as discussed earlier. The Orion AFT ATB is being designed and manufactured by the Launch Systems Group of the Orbital Sciences Corporation, in Chandler Arizona.

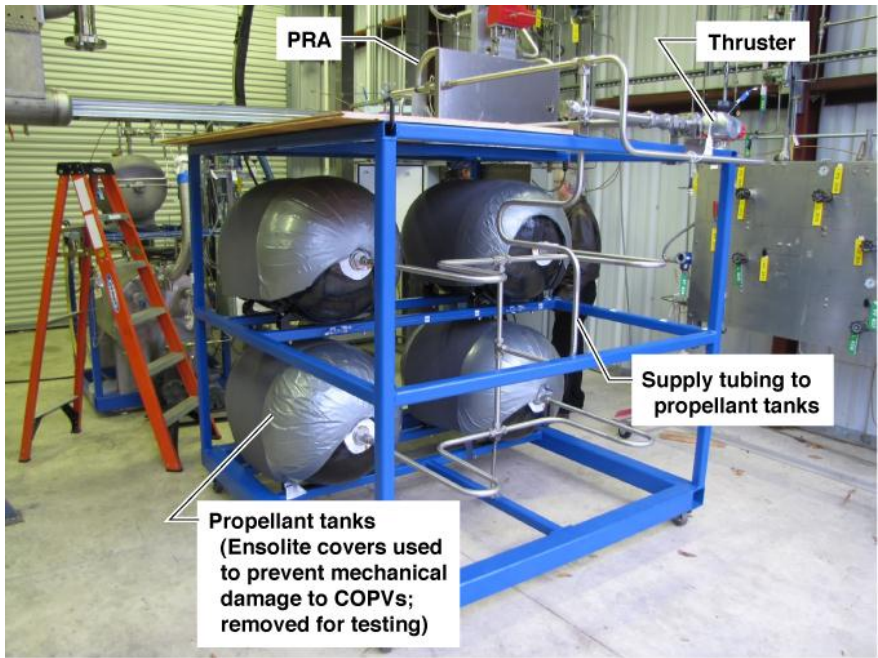

Figure 21. AA-1 RCS developmental testbed.

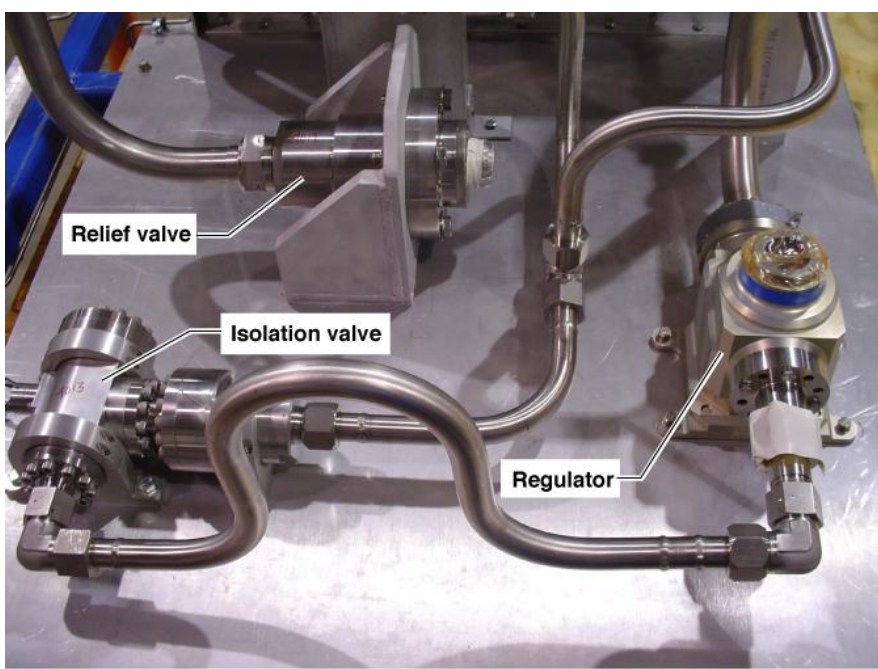

Figure 22. AA-1 RCS developmental testbed, PRA. Orbital is under a contract with the Air Force Space and Missile Systems Center (SMC) Rocket Systems Launch Program (RSLP), located at Kirtland Air Force Base (AFB) in New Mexico. The Orbital Sciences Corporate headquarters is in Dulles, Virginia.

The SR118 was chosen as the booster for the ATB, but it was originally intended for a different purpose. SR118 development was initiated in May 1978 for use as the first stage of the Peacekeeper ICBM. The deployment of the Peacekeeper in 1986 helped to modernize U.S. ICBM assets, and increased strength and credibility of the groundbased U.S. strategic capability. ${ }^{25,26}$ In 2002, it was announced that the Peacekeeper would be deactivated, and a process was begun to remove the missiles from their silos and place them in storage at Hill AFB, in Utah. Once deactivated, the propulsion system assets became the responsibility of the Launch Systems Division (SDL) under the SMC Space Development and Test Directorate (SDTD). Operating within the SMC/SDTD, SDL RSLP is the government agency responsible for maintaining active control of all excess or deactivated land based ICBM assets. TASC Inc. (Chantilly, Virginia) provides independent engineering and mission assurance support to SDL/RSLP, and is the repository for legacy knowledge, modeling, and data for Air Force retired ICBM assets. The purpose for storing Peacekeeper assets is to use the motors for missile defense target and space launches. The motor was designed, manufactured, and qualified by Morton Thiokol, Wasatch Operations in Brigham City, Utah; which is now part of the ATK Aerospace Systems group.

The SR118 is a single solid rocket motor with an overall length of 334 inches, and a case outside diameter of 92 inches. It has an architecture that includes one large partially submerged nozzle with a hydraulic thrust vector system. Figure 23 shows a photo of the SR118 pathfinder; as it is being erected from horizontal to vertical, prior to 
launch stand emplacement at Vandenberg AFB in California. $^{27}$ The SR118 was chosen as the booster for the ATB primarily based on its performance characteristics and reliability. The SR118 has a nominal average thrust of approximately 500,000 lbf, and an action time of several seconds.

The motor is loaded with a conventional propellant, which is ignited with a pyrogen igniter in the forward dome. The case is a continuous filament wound composite that is pre-impregnated with epoxy resin and has an EPDM internal insulation. The SR118 architecture also includes the thrust vector system, providing directional thrust control with the use of an actuation system with two (pitch and yaw) servoactuators for omni-axial vectoring of the nozzle.

Since the primary goal of the Orion AFT Program was focused on testing the Orion LAS in several launch abort scenarios, a highly reliable booster was desired for the ATB which mitigated the risk of a booster

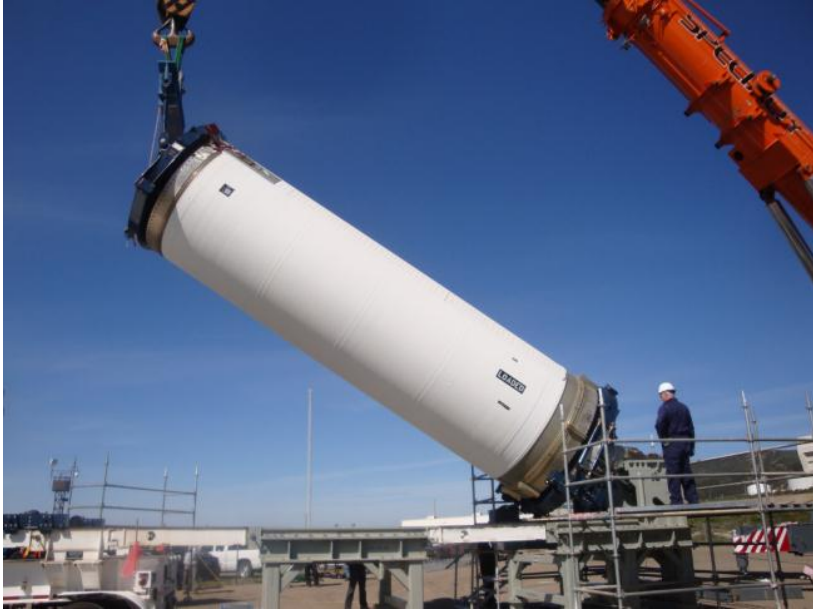

Figure 23. Photo of the SR118 pathfinder as it is being erected from horizontal to vertical, prior to launch stand emplacement at Vandenberg AFB.

failure during flight testing. Therefore, as noted earlier, high reliability was a primary driver in the SR118 booster selection for the ATB. It should also be noted that, early in the Orion AFT Program an ATB QTV was considered, as was conducted on the Apollo LJ-II program, to ensure that the ATB is capable of delivering the Orion LAV to the required abort/separation conditions. The consideration of an ATB QTV was eventually discarded, partially due to the significant static and flight-test history of the SR118.

As of 2007, a total of 35 SR118 static fire tests have taken place, for: development (6), flight proof (4), prequalification (4), qualification (8), production quality assurance (8), and aging surveillance (5). ${ }^{28}$ There have also been over 50 flights on Peacekeeper motors from Vandenberg AFB, in California, with no propulsion failures. ${ }^{28}$ Figure 24 shows a photo of the SR118 during static fire testing at ATK (Promontory, Utah). ${ }^{28}$ Additional SR118 milestones were achieved with the integration and successful flight of three SR118 motors, which were each used as the initial stage on Orbital's Taurus space boosters for the Defense Advanced Research Projects Agency (DARPA) and the USAF SMC RSLP, in 1994, 1998, and $2000 .^{29,30}$ In 2010, Orbital also successfully completed integration and successful flights of three SR118 motors, used as the first stage on their Minotaur IV booster. These missions supported DARPA, SMC, and space test programs under a USAF SMC RSLP contract. ${ }^{31,32}$ In addition to the risk that was mitigated by using a thoroughly static tested and flight-tested solid rocket motor to provide ATB propulsion, the Orion AFT team also has significant SR118 experience with RSLP and the USAF SDTD/SDL as partners.

All of the organizations within the ATB team have worked cohesively since the beginning of the Orion AFT program, with their collective focus on the successful flights of all AA FTVs. In February of 2006 the OrbitalChandler team briefed the NASA AFT team on their technical approach for providing a booster for all AA FTVs; an Orbital-Chandler funded preliminary assessment which was conducted in anticipation that such a vehicle would be required. In January 2007, in response to a Request For Proposal, OrbitalChandler submitted their proposal to NASA and SDTD/SDL for the Orion ATB. In April 2007 Orbital-Chandler was selected as the prime contractor for the ATBs on all the Orion AA FTVs. ${ }^{33}$ Since that time Orbital-Chandler has worked with the USAF SDTD/SDL, TASC/RSLP, and the NASA FTO as part of the Orion AFT team toward the first AA flight with the ATB, and completed their preliminary design review in June of 2008. Figure 25 shows an artist's rendition of a typical AA FTV with the Orbital ATB stacked on the launch pad at WSMR. As of this publication date, the ATB development effort continues making great progress, and Orbital is headed toward their ATB critical design review. Although the full set of four AA flights in the original flight-test manifest has been reduced, the entire ATB team remains determined to help demonstrate the flight-worthiness of the LAS design.

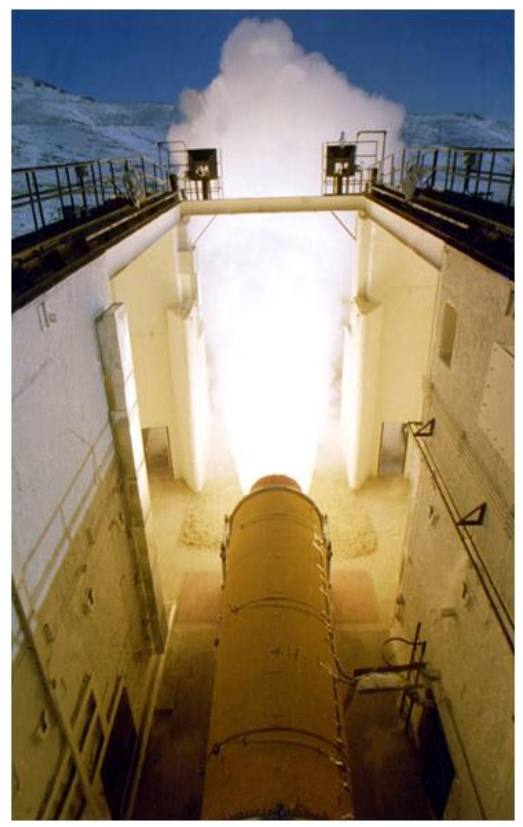

Figure 24. Photo of a typical SR118 during static fire testing. 


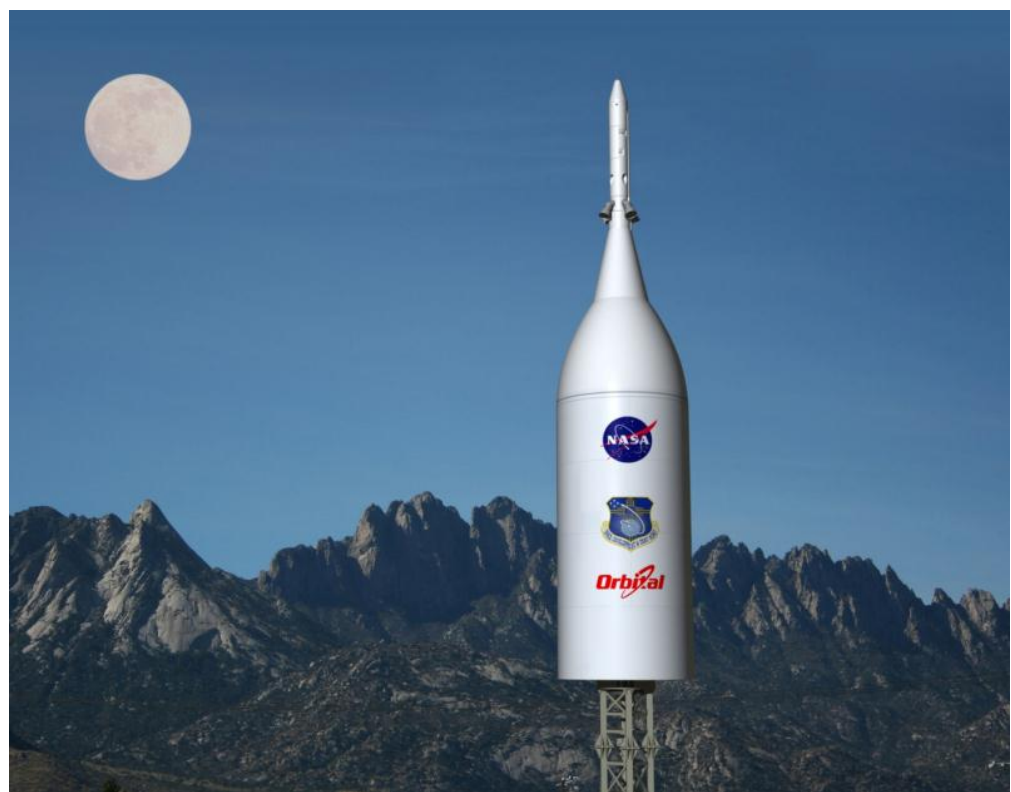

Figure 25. Artist's rendition of a typical AA FTV with the Orbital ATB stacked on the launch pad at WSMR.

\section{Conclusion}

The architecture of any human-rated launch vehicle and spacecraft will always require the greatest level of safety. Increasing crew safety during launch countdown and ascent is the primary goal within the Orion LASO and the Orion FTO, which led to the development and flight testing of the Orion LAS. The Orion PA-1 flight test was the first in what was intended to be a series of flight tests to certify that the Orion LAS is capable of delivering the astronauts aboard the Orion CM safely away from a failed booster. Although the Constellation Program has been cancelled and the operational role of the Orion spacecraft has significantly evolved, several technologies within the Constellation/Orion architecture could certainly be utilized to increase the safety of many future human-rated launch vehicles.

The Orion PA-1 FTV required the use of three propulsive subsystems: the LAS AM, the LAS ACM, and the LAS JM. All three of the LAS motors successfully demonstrated their required functions during the PA-1 flight test. Subsequent Orion FTVs were also being developed, and these required the use of two additional propulsive subsystems: the CM RCS, and the ATB SR118. A brief overview of each of these five subsystems was provided.

Since 2004, several government and private-sector organizations within the LASO and the FTO have been involved in the development and testing of the Orion LAS. This effort involved hundreds of employees across the country with the single goal of increasing the safety of human-rated access to space. The cohesive effort of all the organizations and individuals involved was truly remarkable, and led to the highly successful Orion PA-1 flight test on May 6, 2010.

\section{References}

${ }^{1}$ National Aeronautics and Space Administration, The Vision for Space Exploration, NP-2004-01-334-HQ, February 2004. URL: http://www.nasa.gov/mission_pages/constellation/news/index.html [cited 24 February 2012].

${ }^{2}$ National Aeronautics and Space Administration, Constellation Program Brochure, NP-2008-11-010-JSC, November 2008. URL: http://www.nasa.gov/mission_pages/constellation/news/index.html [cited 24 February 2012].

${ }^{3}$ National Aeronautics and Space Administration Marshall Space Flight Center, NASA facts - Constellation Program: America's Fleet of Next-Generation Launch Vehicles - The Ares I Crew Launch Vehicle, FS-2009-7-133-MSFC, July 2009. URL: http://www.nasa.gov/mission_pages/constellation/news/index.html [cited 24 February 2012].

${ }^{4}$ National Aeronautics and Space Administration Marshall Space Flight Center, Ares I Launch, MSFC-0800205, February 2008. URL: http://www.nasa.gov/mission_pages/constellation/multimedia/aresI_launch.html [cited 24 February 2012].

${ }^{5}$ National Aeronautics and Space Administration Glenn Research Center, NASA facts - Constellation: Orion Crew Exploration Vehicle, FS-2008-07-031-GRC, July 2008. URL: http://www.nasa.gov/mission pages/constellation/news/index.html [cited 28 February 2012]. 
${ }^{6}$ National Aeronautics and Space Administration Press Release 06-299, NASA Names New Crew Exploration Vehicle Orion, August 2006. URL: http://www.nasa.gov/home/hqnews/2006/aug/HQ_06299_Orion_announced.html [cited 28 February 2012].

${ }^{7}$ National Aeronautics and Space Administration Press Release 06-305, NASA Selects Orion Crew Exploration Vehicle Prime Contractor, August 2006. URL: http://www.nasa.gov/home/hqnews/2006/aug/HQ_06305_Orion_contract.html [cited 28 February 2012].

${ }^{8}$ National Aeronautics and Space Administration Langley Research Center, NASA facts - Constellation Program: Astronaut Safety in a Launch Emergency - The Orion Launch Abort System, FS-2008-11-156-LaRC, November 2008. URL: http://www.nasa.gov/mission pages/constellation/news/index.html [cited 28 February 2012].

${ }^{9}$ Tartabini, P. V., "Integrated Flight Performance Analysis of a Launch Abort System Concept," AIAA-2007-6622, August 2007.

${ }^{10}$ National Aeronautics and Space Administration, Project Apollo Archive - Apollo Image Gallery, S69-39961. URL: http://www.apolloarchive.com/apollo_gallery.html [cited 28 February 2012].

${ }^{11}$ Townsend, N. A., "Apollo Experience Report - Launch Escape Propulsion Subsystem," NASA TN D-7083, March 1973.

${ }^{12}$ National Aeronautics and Space Administration, Project Apollo Archive - Apollo Image Gallery, S65-19886. URL: http://www.apolloarchive.com/apollo_gallery.html [cited 28 February 2012].

${ }^{13}$ General Dynamics Convair Division, "Little Joe II Test Launch Vehicle: NASA Project Apollo - Final Report, Volume I: Management," GDC-66-042, May 1966.

${ }^{14}$ National Aeronautics and Space Administration Johnson Space Center, NASA facts - Constellation Program: Orion Project Flight Tests, FS-2007-12-020-JSC, December 2007. URL: http://www.nasa.gov/mission_pages/constellation/news/index.html [cited 28 February 2012].

${ }^{15}$ Williams-Hayes, P. S., "Crew Exploration Vehicle Launch Abort System Flight Test Overview," AIAA-2007-6596, August 2007.

${ }^{16}$ Taylor, J. L., Jr., Cockrell, C. E., Jr., Tuma, M. L., Askins, B. R., Bland, J. D., Davis, S. R., Patterson, A. F., Taylor, T. L., and Robinson, K. L., "Integrated Testing Approaches for the NASA Ares I Crew Launch Vehicle," IAC-07-D2.6.04, September 2008.

${ }^{17}$ US Army/WSMR, Photo of the PA-1 FTV with the PA-1 AFT launch team, April 2010. Available from the Orion Flight Test Management Office, NASA Johnson Space Center, Houston, Texas.

${ }^{18}$ US Army/WSMR, Photo of the PA-1 FTV during launch, May 6, 2010. Available from the Orion Flight Test Management Office, NASA Johnson Space Center, Houston, Texas.

${ }^{19}$ National Aeronautics and Space Administration, Orion Launch Abort System Hydro Proof Test, July 2008. URL: http://www.nasa.gov/mission_pages/constellation/multimedia/Hydro_Proof_Test.html [cited 28 February 2012].

${ }^{20}$ ATK, Orion's Launch Abort System Test Stand Inspection, June 2008. URL:

http://www.nasa.gov/mission_pages/constellation/multimedia/launch_abort_test_2.html [cited 28 February 2012].

${ }^{21}$ National Aeronautics and Space Administration, NASA, ATK Successfully Test First Orion Launch Abort Motor,

November 2008. URL: http://www.nasa.gov/mission_pages/constellation/orion/las_nov08.html [cited 28 February 2012].

${ }^{22}$ ATK, Second Orion Launch Abort System Attitude Control Motor Ground Test, JSC2010-E-041289, March 2010. URL:

http://www.nasa.gov/mission_pages/constellation/multimedia/orion_acm_test2.html [cited 28 February 2012].

${ }^{23}$ Aerojet, NASA Conducts Full-Scale Test Firing of Orion Jettison Motor, July 17, 2008.

URL: http://www.nasa.gov/mission_pages/constellation/multimedia/las_jettison.html [cited 28 February 2012].

${ }^{24}$ American National Standards Institute (ANSI) and American Institute of Aeronautics and Astronautics (AIAA), "Space

Systems - Composite Overwrapped Pressure Vessels (COPVs)," ANSI/AIAA S-081A-2006, July 2006.

${ }^{25}$ United States Air Force, Peacekeeper, 021126-O-9999G-011. URL:

http://www.af.mil/photos/media_search.asp?q=peacekeeper\&page=2 [cited 29 February 2012].

${ }^{26}$ Wikipedia, LGM-118 Peacekeeper. URL: http://en.wikipedia.org/wiki/LGM-118_Peacekeeper [cited 29 February 2012].

${ }^{27}$ TASC/RSLP, Photo of the SR118 pathfinder, as it is being erected from horizontal to vertical, prior to launch stand emplacement at Vandenberg AFB, July 2008. Available from TASC Inc., Chantilly, Virginia.

${ }^{28}$ Johnson, J., Wee, J., and Schoneman, S., "Economic Benefits of Using Previously Procured Air Force Rocket Motors for the Minotaur-family of Launch Vehicles,” AIAA 2007-6012, September 2007.

${ }^{29}$ Orbital Sciences Corporation, Taurus Mission History. URL:

http://www.orbital.com/SpaceLaunch/Taurus/taurus_history.shtml [cited 29 February 2012].

${ }^{30}$ Taurus ${ }^{\circledR}$ Launch System Payload User's Guide, Orbital Sciences Corporation, March 2006. URL: http://www.orbital.com/SpaceLaunch/Taurus/ [cited 29 February 2012].

${ }^{31}$ Orbital Sciences Corporation, Minotaur Mission History. URL: http://www.orbital.com/SpaceLaunch/Minotaur/IV/ [cited 29 February 2012].

${ }^{32}$ Minotaur IV User's Guide, Orbital Sciences Corporation, January 2006. URL:

http://www.orbital.com/SpaceLaunch/Minotaur/IV/ [cited 29 February 2012].

${ }^{33}$ National Aeronautics and Space Administration, NASA Buys Abort Test Boosters for Orion Flight Tests, April 16, 2007. URL: http://www.nasa.gov/home/hqnews/2007/apr/HQ 07086 Orion ATB purchase.html [cited 29 February 2012]. 